\title{
¿Climate Response to Increasing Antarctic Iceberg and Ice Shelf Melt $\mathscr{O}$
}

\author{
SHONA MACKIE AND INGA J. SMITH \\ Department of Physics, University of Otago, Dunedin, New Zealand \\ JEFF K. RIDLEY \\ Met Office, Exeter, United Kingdom \\ DAVID P. STEVENS \\ School of Mathematics, University of East Anglia, Norwich, United Kingdom \\ PATRICIA J. LANGHORNE \\ Department of Physics, University of Otago, Dunedin, New Zealand
}

(Manuscript received 26 November 2019, in final form 4 August 2020)

\begin{abstract}
Mass loss from the Antarctic continent is increasing; however, climate models either assume a constant mass loss rate or return snowfall over land to the ocean to maintain equilibrium. Numerous studies have investigated sea ice and ocean sensitivity to this assumption and reached different conclusions, possibly due to different representations of melt fluxes. The coupled atmosphere-land-ocean-sea ice model, HadGEM3-GC3.1, includes a realistic spatial distribution of coastal melt fluxes, a new ice shelf cavity parameterization, and explicit representation of icebergs. This configuration makes it appropriate to revisit how increasing melt fluxes influence ocean and sea ice and to assess whether responses to melt from ice shelves and icebergs are distinguishable. We present results from simulated scenarios of increasing meltwater fluxes and show that these drive sea ice increases and, for increasing ice shelf melt, a decline in Antarctic Bottom Water formation. In our experiments, the mixed layer around the Antarctic coast deepens in response to rising ice shelf meltwater and shallows in response to stratification driven by iceberg melt. We find similar surface temperature and salinity responses to increasing meltwater fluxes from ice shelves and icebergs, but midlayer waters warm to greater depths and farther north when ice shelf melt is present. We show that as meltwater fluxes increase, snowfall becomes more likely at lower latitudes and Antarctic Circumpolar Current transport declines. These insights are helpful for interpretation of climate simulations that assume constant mass loss rates and demonstrate the importance of representing increasing melt rates for both ice shelves and icebergs.
\end{abstract}

KEYWORDS: Antarctica; Sea ice; Southern Ocean; Climate models; Coupled models

\section{Introduction}

Earth system models (ESMs) link physical processes on land, sea ice, ocean, and atmosphere and the feedbacks between them. In addition to calculating the likely future climate, ESMs are excellent tools for investigating the sensitivity of the climate system to specific processes, providing insights useful for understanding responses to future change. An example of this is the rate at which ice mass is lost from Antarctica, which is the focus of this study. Mass loss from Antarctica has increased in recent years (Rignot et al. 2008; Sutterley et al. 2014; Williams et al. 2014; Martin-Español et al. 2016; Shepherd

\footnotetext{
๖ Denotes content that is immediately available upon publication as open access.
}

Supplemental information related to this paper is available at the Journals Online website: https://doi.org/10.1175/JCLI-D-190881.s1.

Corresponding author: Shona Mackie, shona.mackie@otago. ac.nz et al. 2018) and is likely to continue to increase (Timmermann and Hellmer 2013). Coupling a dynamic ice sheet model with an ESM to realistically capture the changing mass loss rate is technically complex, and most ESMs therefore share the assumption that the rate of mass loss is temporally constant. It is important to understand the effects of this assumption on future climate projections, so as to interpret them appropriately.

Almost all mass loss from the Antarctic continent, with the exception of sublimation, enters the ocean as meltwater. Surface runoff, ice shelf basal melt, and icebergs affect ocean stability and sea ice processes. Near-surface atmosphere, ocean, and sea ice properties and processes are spatially variable, making the ocean and sea ice response to melt fluxes spatially variable. For example, in recent years, Antarctic sea ice extent has increased in some areas and decreased in others (Cavalieri and Parkinson 2008; Turner et al. 2009; Comiso et al. 2011; Pezza et al. 2012; Williams et al. 2014; Parkinson 2019). An appropriate spatial distribution of melt fluxes is therefore likely to be necessary for an accurate representation of their effects on sea ice and the ocean. This should capture the relative melt rates around the Antarctic coast and include the 
effects of iceberg melt, which enters the ocean with a seasonality and spatial distribution dependent on ocean surface properties (and is therefore coupled to atmosphere and ocean processes) (Merino et al. 2016). There are different responses to melt entering the ocean at depth along ice shelf fronts (most ice shelf melt occurs at the grounding line) and at the surface, for example, as iceberg melt (Pauling et al. 2016). Melt entering the ocean at depth is buoyant and rises to the surface, potentially becoming supercooled due to the pressure changes as it does so. The ocean is generally modeled with the surface forming a boundary, and then layers that become thicker as depth increases. The cavity beneath an ice shelf is usually not represented in ESMs because of the technical difficulty of making the cavity shape sensitive to changes in water temperature while avoiding instabilities around the grounding line (Losch 2008). Nonetheless, the modification of surface waters, driven by ice shelf basal melt, can contribute to sea ice formation, and an appropriate representation of melt along ice shelf fronts is needed to accurately represent sea ice processes.

The net of precipitation minus evaporation $(P-E)$ provides the largest freshwater flux to the Southern Ocean (Pauling et al. 2017), and increases can result in increased sea ice concentration (Purich et al. 2018). In the absence of mechanical mixing driven by wind and waves, freshwater from any source can form a buoyant low salinity layer atop the more saline water, increasing the heat content of midlayer ocean waters, which are then prevented from ventilating and exchanging heat with the atmosphere (Hellmer 2004; Richardson et al. 2005; Morrison et al. 2015). Sea ice growth is enhanced by this freshwater-induced stratification, as well as by the higher freezing temperature of the freshwater, and increases in Antarctic melt fluxes are therefore likely to drive increases in sea ice (Turner et al. 2013; Bintanja et al. 2013; Swart and Fyfe 2013; Bintanja et al. 2015; Zunz and Goosse 2015; Pauling et al. 2016, 2017; Bronselaer et al. 2018). The lower atmosphere may be impacted by surface temperature changes driven by the stratification and by changes to the sea ice through the sea ice albedo feedback.

Changes in sea ice may impact on the southern annular mode (SAM), one characteristic of which is the changing latitudinal position of the westerly circumpolar winds surrounding Antarctica, the so-called westerly jet. The position of the jet affects midlatitude weather, and the winds themselves influence the carbon uptake of the ocean (Hoskins and Hodges 2005; Le Quéré et al. 2007). The meridional temperature gradient is projected to steepen under future climate scenarios, driving a strengthening and poleward shift of the jet (Bracegirdle et al. 2013). However, the jet strength and position are also affected by changes in sea ice cover (Bracegirdle et al. 2018), and so may be impacted by changes to freshwater fluxes entering the Southern Ocean.

Many ocean processes are sensitive to freshwater and sea ice and can only be accurately represented if melt fluxes are appropriately represented. For example, freshwater-induced stratification and warming of the subsurface ocean can cause density changes that impact on ocean currents and water formation. Brine rejection during sea ice production can generate High Salinity Shelf Water (HSSW). In key regions, HSSW can sink and spill over the edge of the continental shelf into the deep ocean as Antarctic Bottom Water (AABW). AABW spreads northward and mixes in the abyssal gyres to upwell at lower latitudes and travel poleward as Circumpolar Deep Water (Sloyan 2006). This overturning is a driver of the thermohaline circulation, the primary mechanism by which heat moves around the world's oceans (Weaver et al. 2003; Marsland et al. 2007). AABW production and global ocean circulation may therefore be sensitive to meltwater-induced changes in sea ice (Lago and England 2019; Weaver et al. 2003; Marsland et al. 2007; Stouffer et al. 2007). An analogous process in the Northern Hemisphere drives the Atlantic meridional overturning circulation (AMOC). The AMOC is important to Northern Hemisphere climate (Buckley and Marshall 2016; Sévellec and Fedorov 2016) and is projected to decline as the climate warms (Rahmstorf et al. 2015). Links between the two overturning cells have been found; for example, Weaver et al. (2003) found a freshwater perturbation in the Southern Hemisphere resulted in reduced AABW production, which "reactivated" the AMOC from an "off" state, providing a mechanism by which changes to Antarctic sea ice could impact on Northern Hemisphere climate, and other studies have also found Northern Hemisphere changes to result from an Antarctic meltwater perturbation (Richardson et al. 2005; van den Berk et al. 2019).

Recent ESM developments allow icebergs to be explicitly represented and their transport and melt coupled to ocean surface properties (Marsh et al. 2015). This makes it possible to more appropriately apportion the mass loss from grounded ice between icebergs and ice shelf melt than previously in a coupled model. Combined with updated glaciological estimates of the spatial distribution of Antarctic mass loss (Depoorter et al. 2013; Rignot et al. 2013) and an improved vertical representation of ice shelf melt (Mathiot et al. 2017), it is appropriate to reassess sea ice and ocean responses to increased mass loss scenarios. Merino et al. (2018) investigated this using a coupled ocean-sea ice model with Antarctic mass loss realistically distributed between ice shelves around the Antarctic coast. At each ice shelf, the mass flux was proportioned between melt at the ice shelf front and a calving term for a dynamic iceberg model, using glaciological estimates of calving rates and ice shelf melt. Reanalysis data provided atmospheric forcing. That study found strong regional variations in the sea ice response, highlighting the significance of a realistically distributed melt flux. The findings in Merino et al. (2018) are an important advance in understanding; however, the study made several simplifications that we hope to address here. Sea ice and ocean interactions with the atmosphere have been shown to be important to sea ice processes (Stammerjohn et al. 2008), and the forced atmosphere in Merino et al. (2018) means that these feedbacks were neglected. The use of atmospheric forcing also necessitated salinity restoration and, although this was mostly implemented beyond the northern sea ice edge, freshwater forcing around Antarctica has been shown to affect ocean properties farther north (Richardson et al. 2005). Last, the freshwater perturbation in Merino et al. (2018) was fixed, whereas the changing mass balance of Antarctic ice shelves show that it is accelerating in at least some places (Sutterley et al. 2014; Paolo et al. 2015). Implementing a changing melt flux in a coupled model may reveal additional processes to 
those seen under a constant melt flux. Recently, Bronselaer et al. (2018) used climate projections from the CMIP5 experiment as external forcings for an ice sheet model, and so calculated increases in Antarctic mass loss realistic for an assumed future emissions scenario. The calculated mass loss rates were distributed uniformly around the coast as a surface melt flux in an ESM, and ocean and sea ice responses were assessed. While those findings provide useful insights into likely future changes driven by increased Antarctic melt, the results depend on the assumed future emissions scenario and do not account for meltwater entering the ocean at depth or with a nonuniform spatial distribution, which is likely to impact local sea ice. A study by Schloesser et al. (2019) highlights the importance of icebergs to the distribution of meltwater entering the Southern Ocean. An ice sheet model was used to partition Antarctic mass loss between icebergs and meltwater entering the ocean at the coastal ice shelves. Future emissions scenarios provided external forcings to assess the likely effect of icebergs and ice shelf melt on future climate. In that work, the two meltwater pathways resulted in different effects on surface ocean and atmosphere temperatures, and iceberg meltwater effects were found to depend on the size of the icebergs and on the ocean properties that determined their trajectories. Using future emissions scenarios makes that study a useful indicator of future climate under different scenarios, but it is not straightforward to isolate effects attributable to the increasing meltwater fluxes from those attributable to changes in other external forcings (e.g., interactions between effects from increasing $\mathrm{CO}_{2}$ and from increasing meltwater fluxes are nonlinear; Mackie et al. 2020b). Furthermore, Schloesser et al. (2019) did not include a parameterization for the ice shelf cavity and considered both ice shelf and iceberg meltwater as a surface flux. In reality, icebergs are rarely as deep as ice shelf grounding lines, where most ice shelf melt occurs, and meltwater entering the ocean at depth may have different effects to a surface meltwater flux (Pauling et al. 2016).

Here, we investigate sea ice and ocean responses to an increasing rate of Antarctic mass loss. We implement the dynamic iceberg scheme from Marsh et al. (2015) in a fully coupled atmosphere-ocean-sea ice climate model. To our knowledge, this is the first study into the sensitivity of a fully coupled climate model to an increasing rate of mass loss from Antarctica, where icebergs are explicitly represented and the melt flux is distributed using a realistic spatial distribution and an improved parameterization of the ice shelf cavity. We isolate the sensitivity to increasing meltwater by assuming an unchanging preindustrial emissions scenario and investigate the effect of the increasing Antarctic mass loss rate (a further experiment assesses the sensitivities in the context of increasing $\mathrm{CO}_{2}$ levels; Mackie et al. 2020b). We also examine whether the role of ice shelf melt on ocean and sea ice characteristics is distinguishable from that of iceberg melt.

\section{Method}

\section{a. Model description}

We use the coupled land-ocean-atmosphere-sea ice model, HadGEM3-GC3.1 (Williams et al. 2018; Kuhlbrodt et al.
2018). We refer to Storkey et al. (2018) for a description of the ocean component, version 6 of the U.K. Global Ocean configuration (GO6, based on NEMO; Madec and the NEMO Team 2016), and to Ridley et al. (2018) for a description of the sea ice component, Global Sea Ice 8.1 (GSI8.1, based on CICE 5; Hunke et al. 2015). Melt-freeze processes in GSI8.1 depend on ocean salinity, so freshening the surface waters is anticipated to lead to increased sea ice concentration. The simulations use the ORCA 1 grid (nominally $1^{\circ}$ resolution) for the ocean and sea ice components, and an atmospheric resolution of $1.875^{\circ}$ by $1.25^{\circ}$, with 75 vertical layers in the ocean, and 85 levels for the atmosphere. In the standard configuration, the rate of Antarctic mass loss remains constant at $1770.75 \mathrm{Gt} \mathrm{yr}^{-1}$. This figure was calculated as the rate of mass loss, assumed constant, that would keep the Antarctic ice sheets in mass balance in the model over 100 years with preindustrial forcings, and consequently results in no ocean salinity drift (in simulations of future climate change, increasing accumulation over Antarctica will intentionally result in sea level fall). A small amount of accumulation is lost through sublimation and surface melt (determined by atmospheric conditions over the continent), and the remainder is distributed as a mass flux that enters the ocean through ice shelves around the Antarctic coast (the latter processes dominate the mass loss mechanism by several orders of magnitude; Liston and Winther 2005), proportioned between these according to the distribution in Rignot et al. (2013). At each ice shelf, an iceberg calving flux accounts for $45 \%$ of the mass loss and $55 \%$ is depicted as ice shelf basal melt. The ice shelf cavity is not explicitly represented, instead basal melt enters the ocean at the ice shelf front, distributed evenly between model levels spanning the vertical range of the ice shelf draft, following the parameterization in Mathiot et al. (2017). The Lagrangian iceberg scheme (Marsh et al. 2015) creates icebergs at the ice shelf front using the size distribution from Bigg et al. (1997), with horizontal dimensions from $100 \mathrm{~m} \times 67 \mathrm{~m}$ up to $1.5 \mathrm{~km} \times 1 \mathrm{~km}$. Simulated icebergs must be small relative to a model grid cell (cells become smaller at high latitudes) because they exist only as a meltwater source and are effectively "invisible," that is, solar radiation reaching the ocean is not impacted by their presence. Once calved, iceberg motion is determined by drag on the iceberg from the atmosphere, ocean, and sea ice (a wave radiation forcing is also applied, following Martin and Adcroft 2010). The drift of modeled icebergs may be slowed sufficiently to represent their becoming grounded. There is no momentum exchange between icebergs and sea ice, and sea ice is unaffected by the icebergs. The dominant mechanism for iceberg decay is wave erosion, but this only occurs when the icebergs are surrounded by ocean, and decreases linearly with increasing sea ice concentration to be zero when an iceberg is in a grid cell with $100 \%$ sea ice cover (Martin and Adcroft 2010). Model iceberg decay is otherwise accounted for by basal melt, determined by the ocean surface temperature plus $4^{\circ} \mathrm{C}$ (to approximate the temperature at $500 \mathrm{~m}$ depth). The latent heat associated with iceberg melt cools the surface ocean. Modifications to improve this scheme and allow icebergs to interact with the subsurface ocean have been proposed (Merino et al. 2016) but are not included in HadGEM3-GC3.1, and icebergs in our 


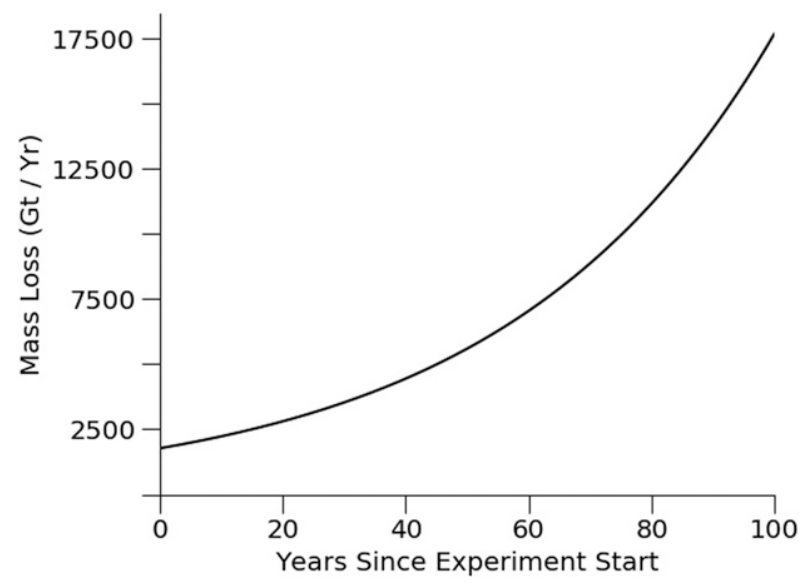

FIG. 1. The total rate of mass loss from the Antarctic continent in the experiments.

study do not interact with the subsurface ocean. Processes for mass loss in the Arctic are similar, with mass loss from the Greenland Ice Sheet fixed at a constant rate. However, in HadGEM3-GC3.1 Greenland is assumed to have no ice shelves, and so the residual from the surface mass balance enters the ocean solely as icebergs.

\section{b. Experiments}

Three experiments were undertaken to assess the effect of an increasing rate of Antarctic mass loss, relative to the HadGEM3-GC3.1 preindustrial control simulation submitted to CMIP6 (PIControl). In all the experiments, the total rate of mass loss increases by $2.33 \%$ each year for 100 years, so that the final rate is 10 times the initial rate (Fig. 1). The scenario was designed to look at the sensitivity of the modeled ocean and sea ice to the increasing rate of mass loss, rather than to be realistic in terms of absolute numbers. For context, however, the freshwater contribution from Antarctica to the Southern Ocean could rise above $1 \mathrm{~Sv}\left(1 \mathrm{~Sv} \equiv 10^{6} \mathrm{~m}^{3} \mathrm{~s}^{-1}\right)\left(31104 \mathrm{Gt} \mathrm{yr}^{-1}\right.$ using HadGEM3-GC3.1's 360-day model year) by 2100 under RCP8.5 (DeConto and Pollard 2016; Schloesser et al. 2019; van den Berk et al. 2019), which is almost twice the maximum reached in our experiments $\left(17707.5 \mathrm{Gt} \mathrm{yr}^{-1}\right)$. Mass loss from the Greenland Ice Sheet remains as per the standard model in all experiments, and all forcings other than Antarctic mass loss are equal to those in PIControl. The first experiment, labeled FW, investigates the sensitivity of the modeled ocean and sea

TABLE 1. Summary of experiment and control simulation settings. Note that these refer to Antarctic mass loss only, and the mass loss from Greenland remains as per the standard model configuration in all runs.

\begin{tabular}{lccc}
\hline \hline Simulation & Increasing mass loss & Icebergs & Ice shelf melt \\
\hline PIControl & No & Yes & Yes \\
FW & Yes & Yes & Yes \\
FWShelf & Yes & No & Yes \\
FWBerg & Yes & Yes & No \\
\hline
\end{tabular}

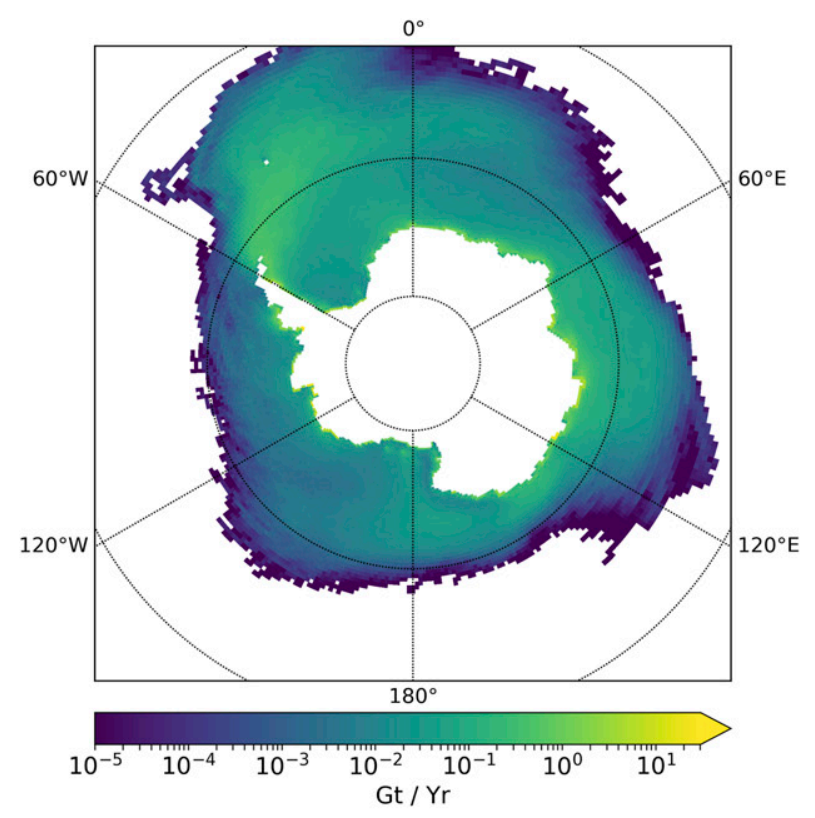

(a) PIControl

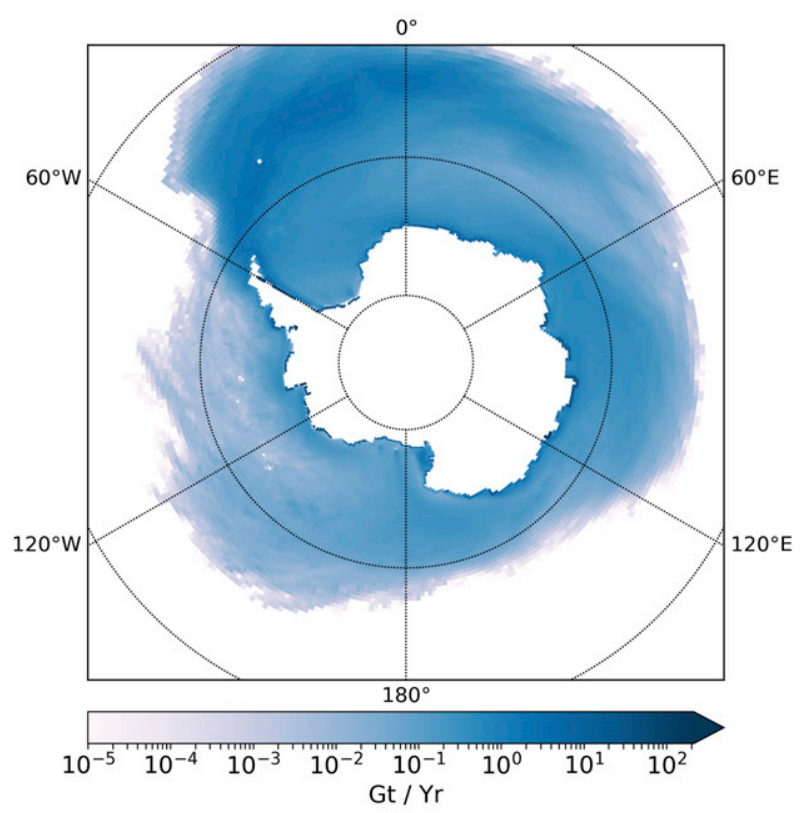

(b) FW - PIControl

FIG. 2. (a) Mean spatial distribution of total melt flux for PIControl. (b) The mean anomaly for the final 20 years of FW. To make ice shelf melt discernible in coastal grid cells, no land mask is plotted. Dotted lines mark meridians as labeled and parallels at $40^{\circ}$, $60^{\circ}$, and $80^{\circ} \mathrm{S}$.

ice to the increasing mass loss, proportioning the loss at the coast between ice shelf melt and an iceberg calving flux, as for PIControl. The second and third experiments, FWShelf and FWBerg, consider whether effects attributable to increasing 


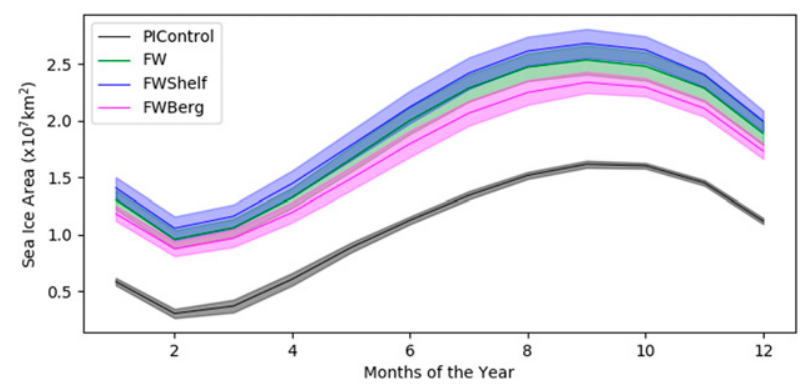

FIG. 3. The response of the SIA seasonal cycle to the increased freshwater flux. The mean seasonal cycle is calculated over the $100-y r$ study period for PIControl and over the final 20 years for the experiments. Shading shows 1 standard deviation for the month.

iceberg and ice shelf melt can be differentiated. The iceberg calving rate for Antarctic ice shelves is highly variable but is assumed to be constant in the standard model configuration. If we can distinguish between the climate response to increased melt at ice shelf fronts and increased melt from icebergs, then it may be appropriate to find a more detailed parameterization for iceberg melt, and there may be implications for projections from climate models without explicit iceberg representation. In the Southern Hemisphere, no icebergs are calved in FWShelf and all melt enters the ocean as ice shelf basal melt, while in FWBerg there is no ice shelf melt and all mass loss enters the ocean at the surface as an iceberg melt flux. FWShelf and FWBerg isolate responses separately attributable to iceberg or ice shelf melt, but in reality (and in FW), the effects of iceberg and ice shelf melt are not independent (ice shelf melt may cool surface waters and so inhibit iceberg melt). Configurations for the experiments are summarized in Table 1, and the data are available in Mackie et al. (2020a). The drift in PIControl is about $0.01 \mathrm{~K}$ per century. Where anomalies are used to show differences between the experiments and PIControl, the values compared represent averages over multiple years and no fitting is performed. Anomalies are computed by subtracting the PIControl value from the value for the same diagnostic in the experiment for the equivalent model time period. Otherwise, the experiments and PIControl are presented as time series of absolute values, rather than as anomalies.

The mean spatial distribution of the melt flux in PIControl is shown alongside the anomaly for the final 20 years of FW in Fig. 2. The spatial distribution of ice shelf melt and iceberg calving is unchanged throughout the experiments, although icebergs may follow different trajectories and so alter the iceberg melt distribution.

\section{Results}

\section{a. Sea ice area and volume}

Sea ice area (SIA) increased in all the experiments; however, there was no shift in the timing of the seasonal cycle (with the caveat that these data represent monthly averages) as a result of the melt anomaly (Fig. 3). This is perhaps surprising, since iceberg melt introduces a seasonality that is enhanced in FWBerg and removed altogether in FWShelf. Antarctic sea ice

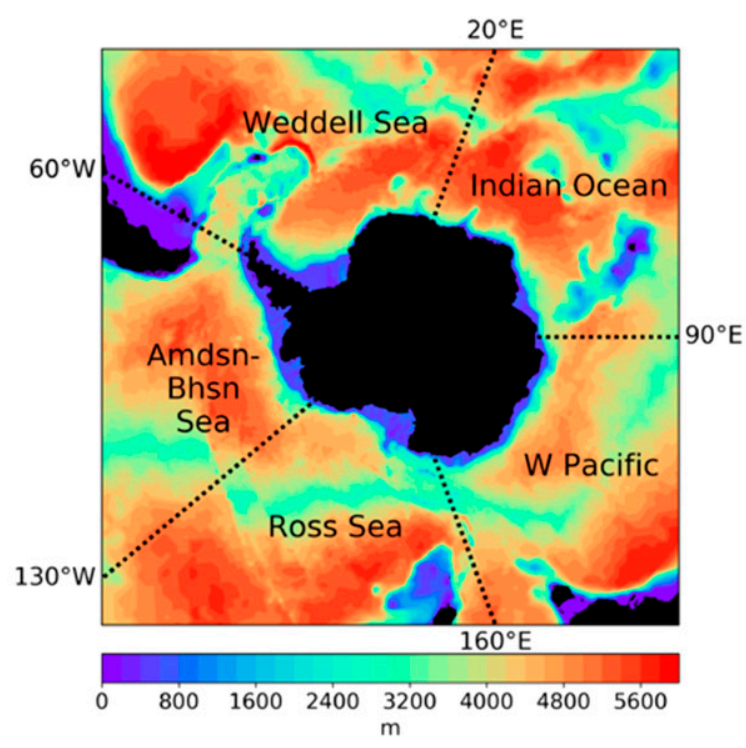

(a)

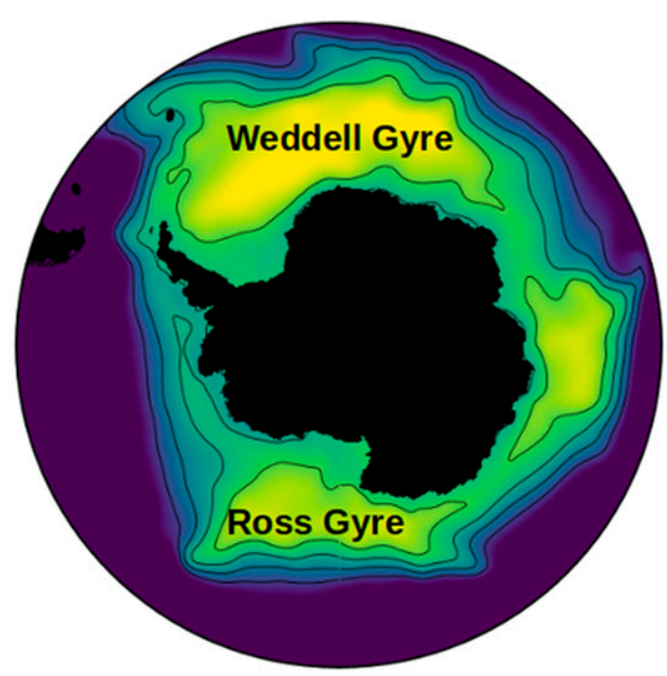

$\mathrm{m}$

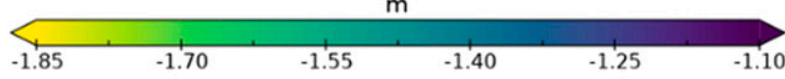

(b)

FIG. 4. (a) Bathymetry, with the ocean sectors used for discussion of sea ice effects overlaid. (b) Model sea surface height, with closed contours indicating the centers for the Ross and Weddell Gyres. Note that the flow direction is clockwise for the gyres, and the Antarctic coastal current flows anticlockwise around the continent.

trends are spatially variable (Cavalieri and Parkinson 2008), and so we consider the sea ice response separately for the different ocean sectors in Fig. 4 (sectors follow Yuan et al. 2017). The total melt flux and the SIA for the experiments and for PIControl are plotted for these sectors in Figs. 6 and 5, and discussed in the following paragraphs. 


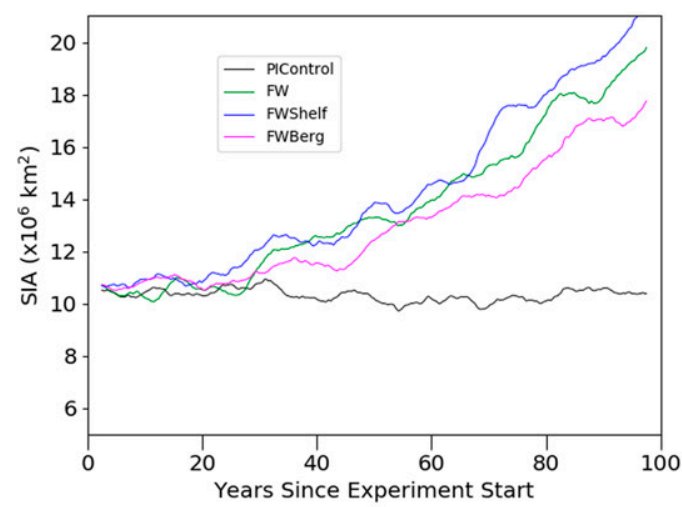

(a) Total

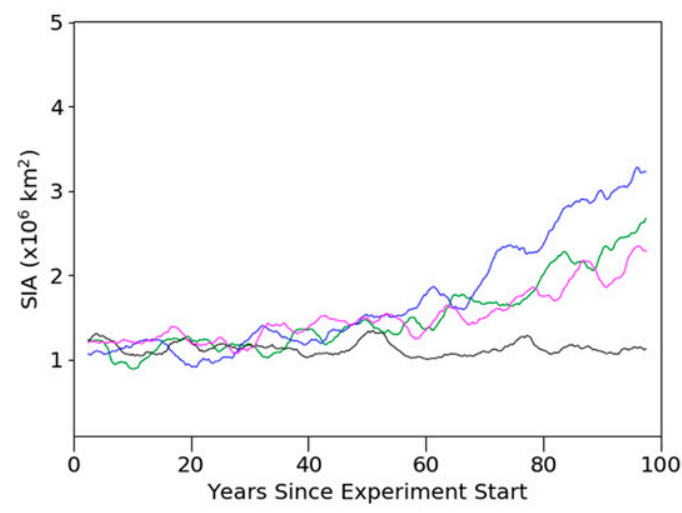

(c) Amdsn-Bhsn Sea

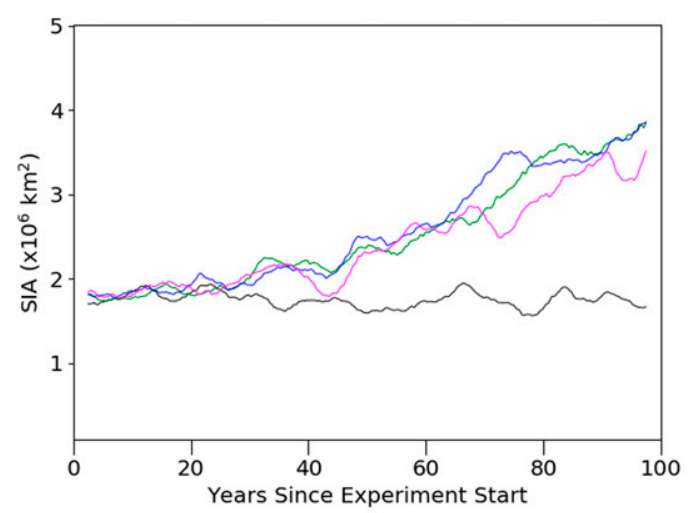

(e) Indian Ocean

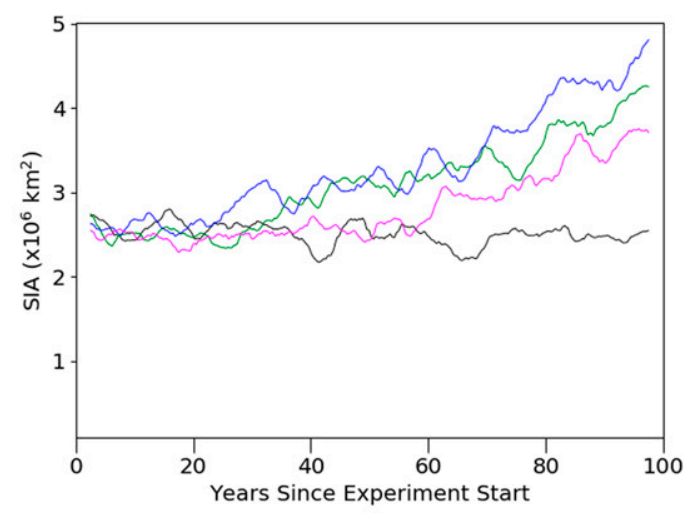

(b) Ross Sea

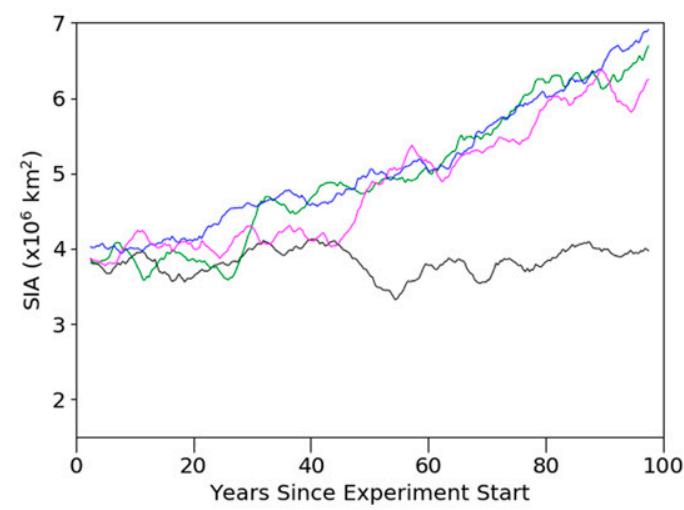

(d) Weddell Sea

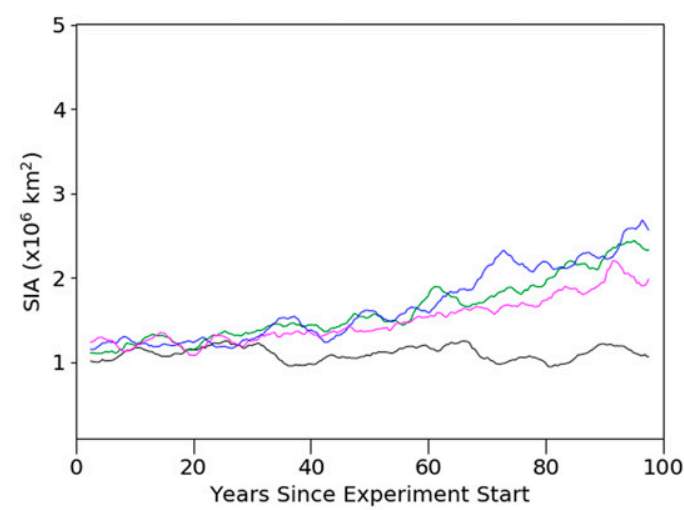

(f) Western Pacific

FIG. 5. Evolution of SIA in the experiments and in PIControl: (a) whole Southern Hemisphere; (b) Ross Sea; (c) Amundsen-Bellingshausen Sea; (d) Weddell Sea; (e) Indian Ocean; (f) western Pacific (5-yr running mean). Note the different scales for different sectors.

In all of the experiments, SIA follows PIControl initially, and then increases in all sectors (Fig. 5). The only differences between the effects driven by the different melt sources are the timing and magnitude of the increase. In FWShelf, the increase in SIA begins earlier than in FW and FWBerg where the time taken for icebergs to melt introduces a delay (icebergs also have the effect of displacing the melt flux so that some of it enters the ocean farther north, where it is less likely to impact sea ice growth). FWShelf therefore results in the strongest SIA impact and FWBerg the weakest (and most variable), with FW driving a response in between the two.

In all three experiments, the SIA response in Fig. 5 is stronger in the Ross Sea sector than in the Indian Ocean and western Pacific, despite similar increases in the volume of melt input in these regions (Fig. 6). The meltwater received by the Ross Sea sector is likely to be supplemented by both ice shelf 


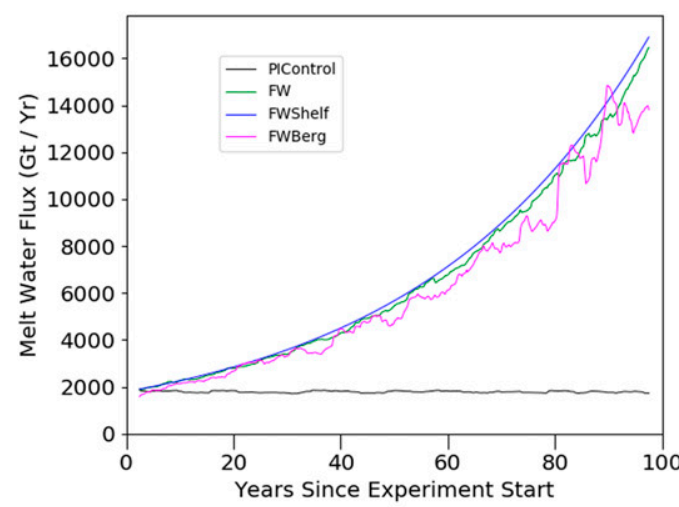

(a) Total

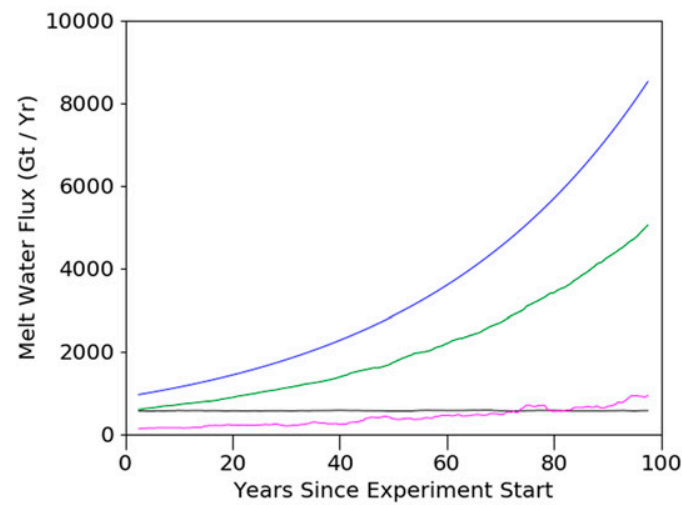

(c) Amdsn-Bhsn Sea

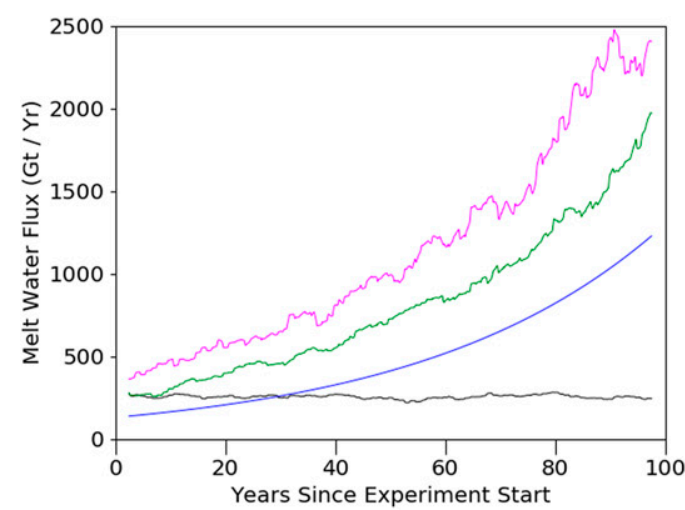

(e) Indian Ocean

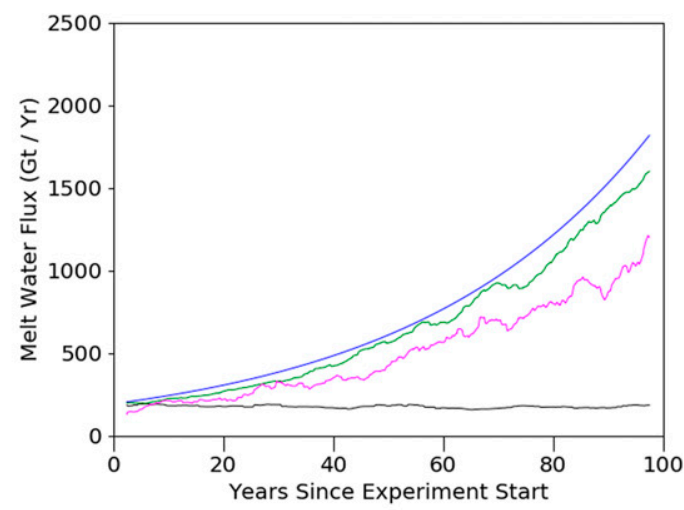

(b) Ross Sea

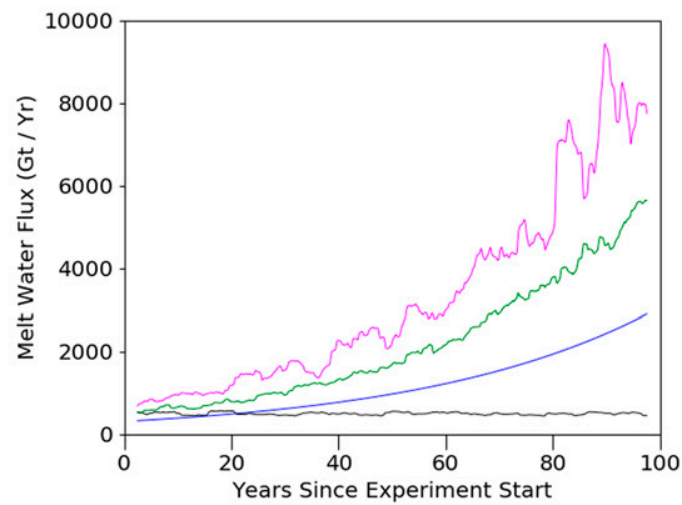

(d) Weddell Sea

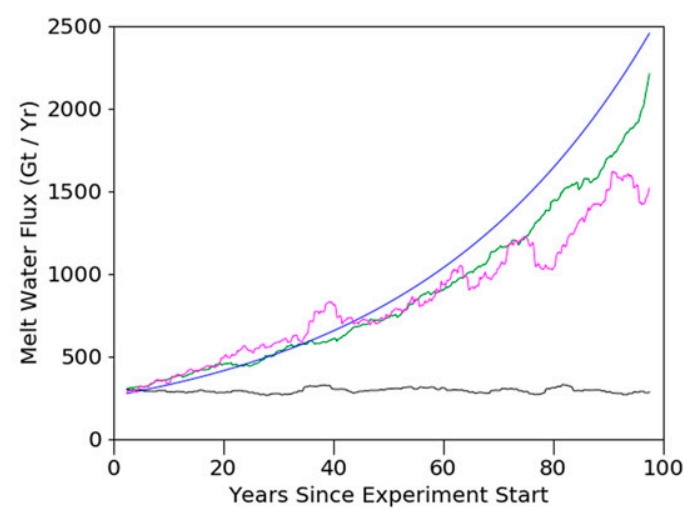

(f) Western Pacific

FIG. 6. As in Fig. 5, but for total meltwater flux from ice shelf and iceberg melt in all the experiments.

melt and icebergs transported from the Amundsen-Bellingshausen Sea by the coastal current and the Ross Gyre, resulting in a stronger SIA response in the Ross Sea than can be attributed solely to increases in local ice shelf melt and melt from locally calved icebergs. The transport of icebergs means that FWBerg results in very little, if any, additional melt entering the Amundsen-Bellingshausen Sea relative to PIControl. In FWShelf, the additional melt entering the Amundsen-Bellingshausen Sea sector is higher than in other sectors, but the SIA response is relatively weak as some of the meltwater is transported out of the sector similarly to the icebergs in the other experiments. The additional melt volume received by the Weddell Sea and Indian Ocean sectors in FWBerg is much greater than in FWShelf, suggesting that icebergs enter these areas from elsewhere. The magnitude of the SIA response, however, is similar for all three experiments in these sectors, since a high proportion of the icebergs in these regions melt farther north (Fig. 2), where they are less likely to impact sea ice growth. The 


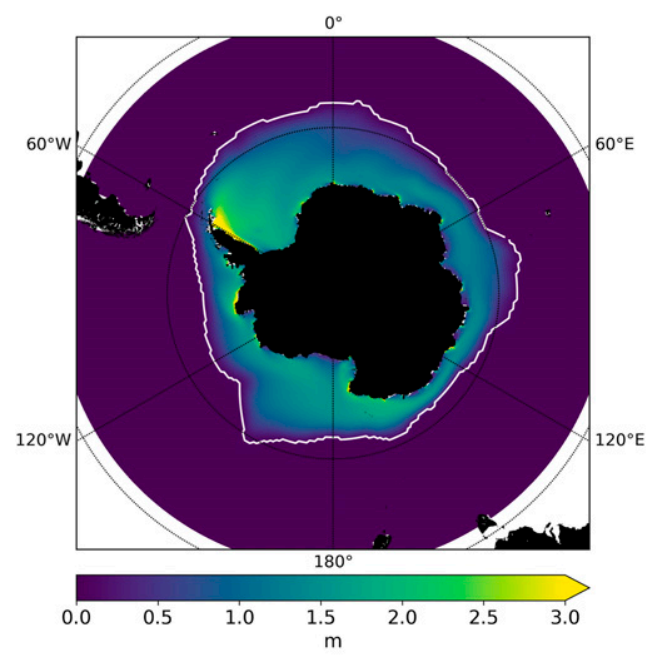

(a) PIControl

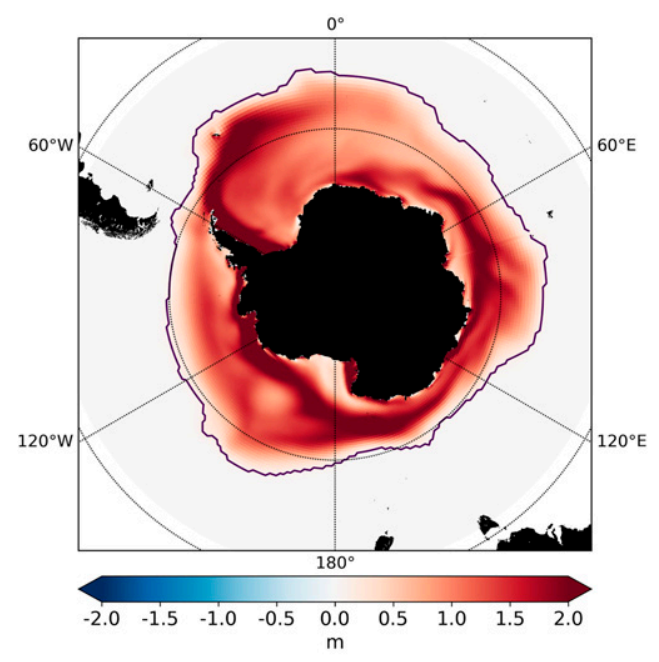

(c) FWShelf - PIControl

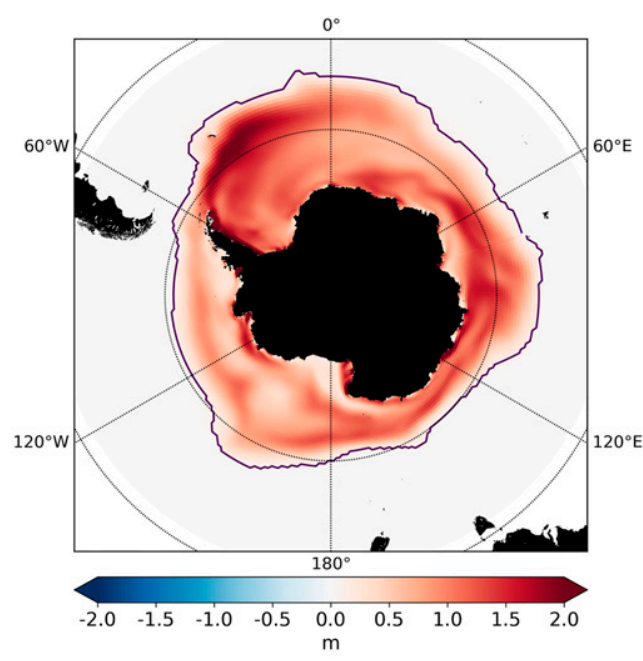

(b) FW - PIControl

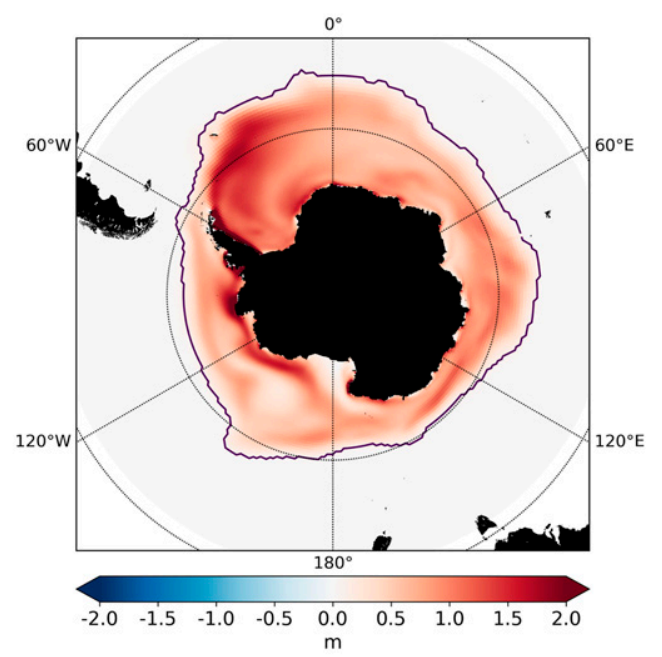

(d) FWBerg - PIControl

FIG. 7. (a) Mean September sea ice thickness (SIT) in PIControl, and SIT anomaly for the final 30 years of the experiments: (b) FW, (c) FWShelf, and (d) FWBerg. The solid contour [white in (a); black in (b)-(d)] shows the mean September sea ice extent (the area beyond which the sea ice concentration in a grid cell does not exceed $15 \%$ ). Dotted lines mark meridians as labeled and parallels at $40^{\circ}$ and $60^{\circ} \mathrm{S}$.

SIA response is weakest in the western Pacific for all experiments, and all three experiments correspond to similar increases in melt here (relative to PIControl).

Local differences in the sea ice response to FWShelf and FWBerg indicate areas where sea ice growth is primarily driven by ice shelf melt. These areas are less accessible to icebergs, and/or have surface water that is cold enough (without ice shelf melt-induced cooling) to suppress iceberg melt. By the end of FWShelf, sea ice thickening is particularly strong along the Amundsen-Bellingshausen Sea coast and the eastern coast of the Antarctic Peninsula, where ice shelf basal melt is strongest (Fig. 7). FWShelf also has a sea ice thickness anomaly at the continental shelf break and along the eastern coast in the
Ross Sea that is largely absent in FWBerg (see Fig. 4 for bathymetry). In the earlier part of FWBerg (Fig. S1 in the online supplemental material), there is a slight reduction in ice concentration in the northern Ross Sea, indicating that growth here is initially driven by the ice shelf melt that is absent in FWBerg. Along the western coast of the Antarctic Peninsula, the earlier part of FWShelf results in a small decrease in ice concentration, suggesting that icebergs are important to sea ice growth here. The different spatial distribution of the thickness response does not directly follow the distribution of the meltwater input. For example, thickening northward from the coast, where the meltwater input is higher in FWBerg, is much stronger in FWShelf than FWBerg, due to advection of the ice shelf meltwater. 


\section{b. Sea ice formation processes}

To assess which sea ice processes were enhanced or inhibited by the additional meltwater, sea ice volume anomalies attributed to specific growth and decay processes were examined. The full volume budget includes growth through frazil formation, congelation, and snow-to-ice conversion; decay through top, lateral, and basal melt; and surface sublimation. Snow-toice conversion, lateral melt, sublimation, and top surface melt remained largely unchanged in the experiments and we therefore only discuss changes to the other budget terms. Congelation growth is the downward growth (thickening) of existing sea ice into the ocean as a result of the atmosphereocean temperature difference. As the ice thickens, the temperature gradient through the ice weakens and congelation growth declines (Fig. S2 in the online supplemental material shows the relationship between thickness and congelation growth rate). Frazil growth is the freezing of ice crystals that have accumulated at the ocean surface or beneath existing sea ice. In the model, these ice crystals are formed when surface waters are supercooled (in the real world, supercooling can also lead frazil to form at depth; Smith et al. 2001, 2012; Langhorne et al. 2015). Figure 8 shows the change in the proportion of the sea ice volume budget that is accounted for by these different processes.

In all three experiments, congelation growth is initially unaffected by the additional melt, but becomes inhibited as the sea ice thickens, altering the temperature gradient through the ice. FWShelf shows the greatest reduction in congelation growth, corresponding to the strongest thickening. Sea ice basal melt decreases as it depends on the freeze-melt temperature of the surface waters, which increases in all three experiments as the water freshens. Reduced sea ice basal melt therefore increases the sea ice volume similarly in all experiments. Frazil production increases in response to the rising of the increased volumes of supercooled melt entering the ocean at depth along the ice shelf fronts in FWShelf and FW, and additionally in response to a local overturning driven by this rising meltwater (discussed in section 3 ). The frazil response is therefore stronger, and begins earlier, in the experiments that include ice shelf melt in Fig. 8. Some increase in frazil production occurs in FWBerg (Fig. 8c) in response to increased sea ice growth at the fringes of the ice pack where iceberg melt raises the freezing temperature of the ocean surface. In all three experiments, reduced sea ice basal melt contributes strongly to sea ice growth, but frazil production is the dominant driver for growth in experiments that include ice shelf melt.

\section{c. Watermass formation}

The additional meltwater in the experiments may change where sea ice forms, with implications for watermass formation associated with sea ice production. The salt flux into the ocean from sea ice freeze-melt can be used to discriminate areas of sea ice production in the model. Although sea ice is relatively fresh, the finite salt budget of the ocean means that freezing ocean is associated with a negative salt flux (since salt is removed, albeit in low concentration relative to the volume of water removed). Conversely, melting sea ice corresponds to a positive flux since the salt is returned to the ocean. The salt flux

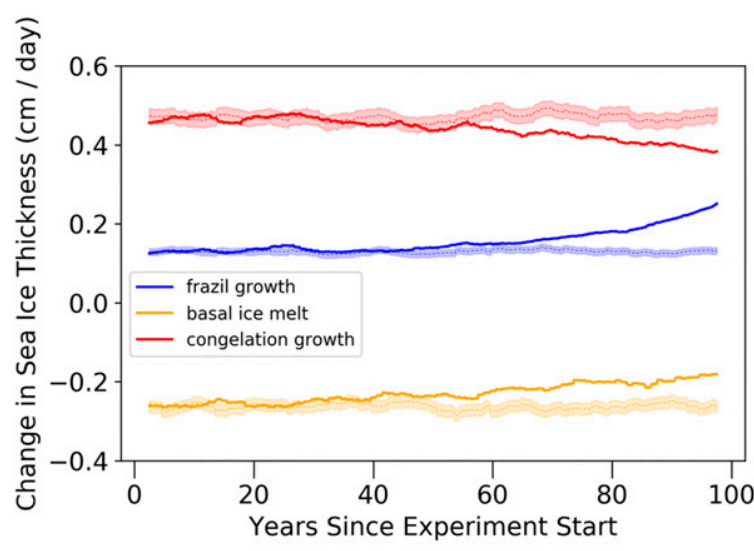

(a) FW

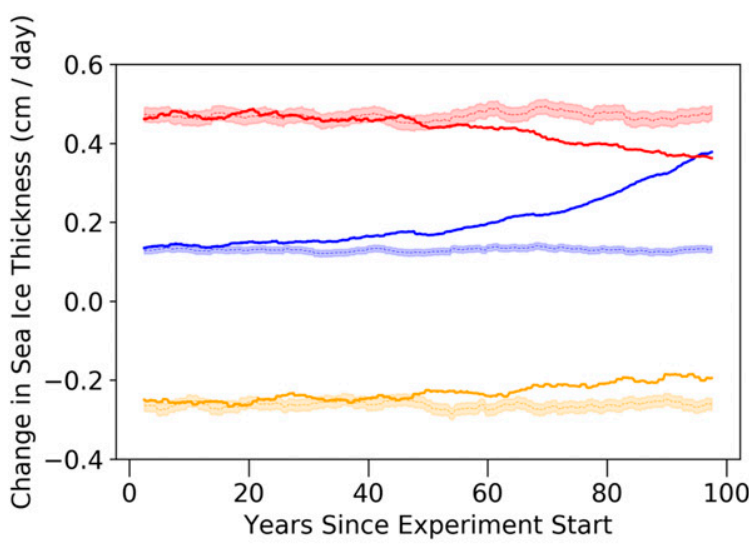

(b) FWShelf

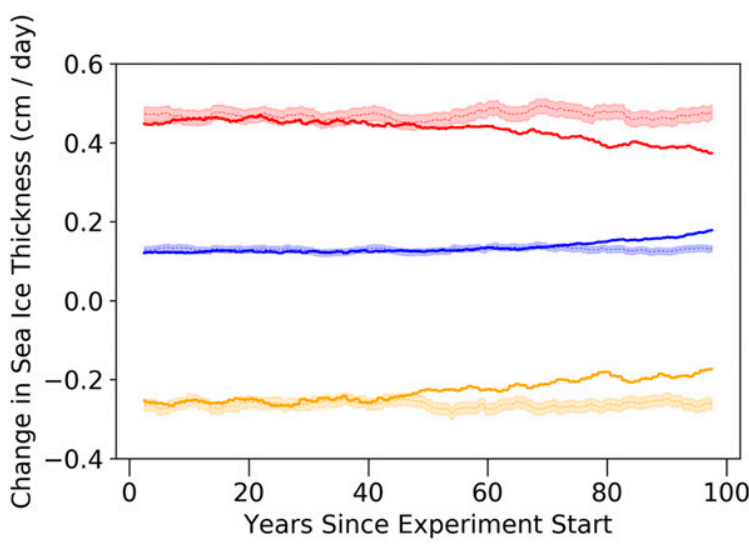

(c) FWBerg

FIG. 8. Change in SIT attributable to each process, averaged over all sea ice areas for (a) FW, (b) FWShelf, and (c) FWBerg. Blue: frazil growth; orange: basal ice melt; red: congelation growth. Experiments are shown as solid lines, and PIControl is shown as a dashed line, with shading to show \pm 1 standard deviation. Plots show the 5 -yr running mean. 


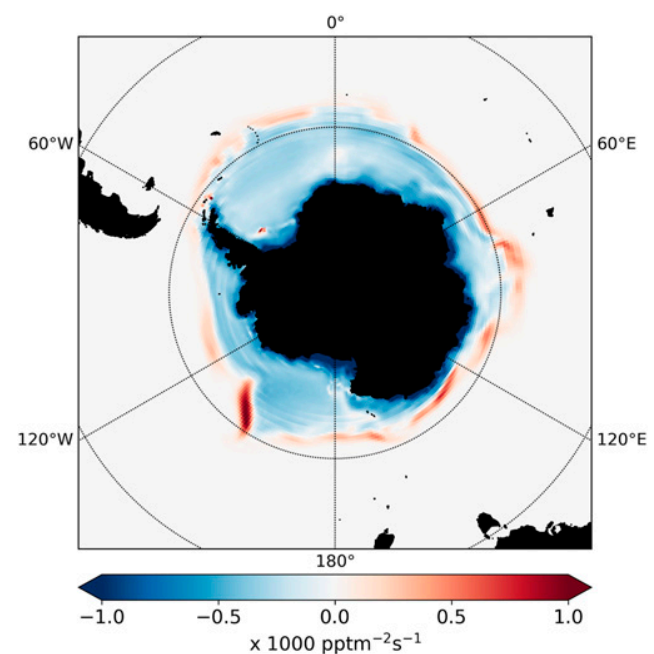

(a) PIControl

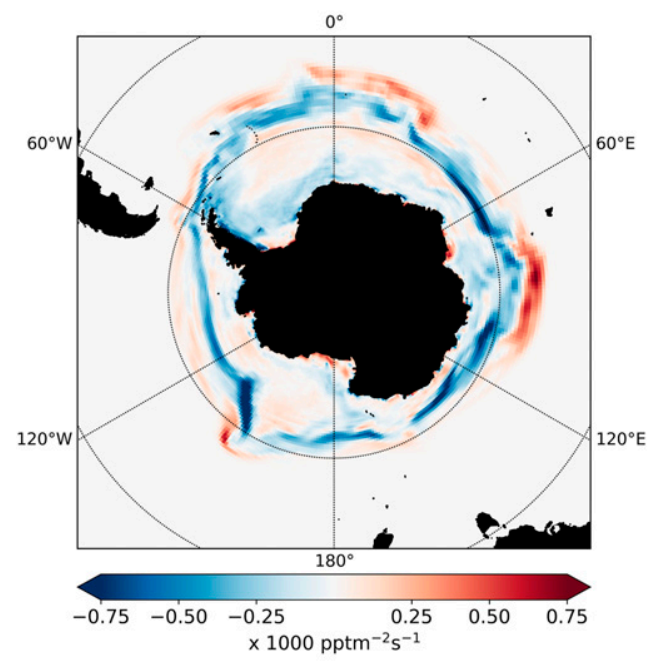

(c) FWBerg - PIControl

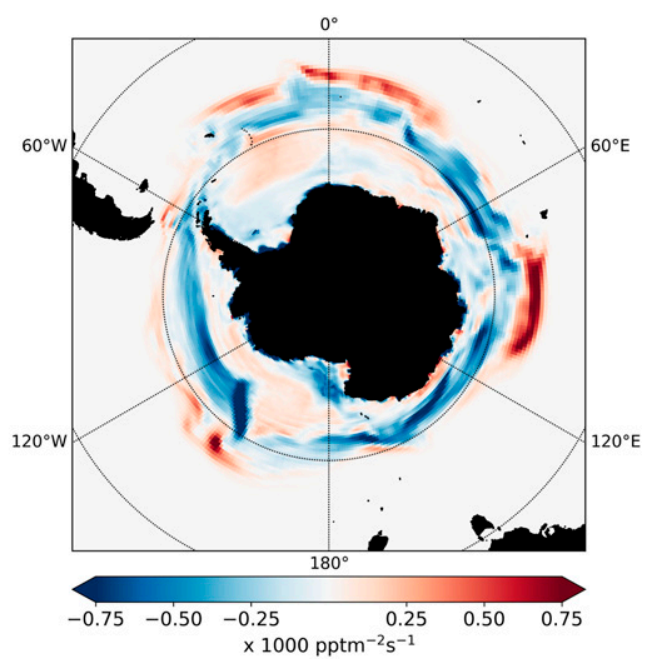

(b) FWShelf - PIControl

FIG. 9. (a) The mean salt flux into the ocean for September for PIControl, and the September anomaly averaged over the final 30 years of the experiments: (b) FWShelf and (c) FWBerg. Dotted lines mark meridians as labeled and parallels at $40^{\circ}$ and $60^{\circ} \mathrm{S}$. See the text for a description of the salt flux as a proxy for sea ice formation and melt.

is therefore a proxy for sea ice growth, and a negative (positive) anomaly indicates increased (reduced) sea ice growth. The converse applies for melt (Fig. 9). In PIControl, most ice production occurs in shore leads on the coast (dark blue areas), and southerly winds force the ice northward, where it thickens further (lighter blue areas). At the northern extent of the sea ice, the ice melts, creating a "melt edge" (shaded red because salt from the ice is returned to the ocean). In the experiments, the melt edge has moved north. There are some differences between the sea ice production response over the continental shelf in FWShelf and FWBerg (see Fig. 4 for bathymetry). For example, in the Ross Sea and close to the coast in the Weddell Sea, production increases in FWShelf (Fig. 9b) and decreases slightly in FWBerg (Fig. 9c).
Sea ice production is often associated with a deepening mixed layer, as brine rejection creates sinking dense saline water that drives convection. This can be countered by high basal melt rates at some ice shelf fronts that inhibit the salinitydriven deepening of the mixed layer and associated deep convection (Silvano et al. 2018). However, in FWShelf there is a deepening of the mixed layer close to the coast, despite high ice shelf basal melt rates, even in areas where sea ice production has not increased (Fig. 10). This deepening around the coast, which does not occur in FWBerg, reflects a local overturning driven by the high volume of ice shelf melt entering the ocean at depth and rising to the surface in FWShelf, as also found in Pauling et al. (2016) and explained in Merino et al. (2018). As ice shelf melt increases, the overturning strengthens 


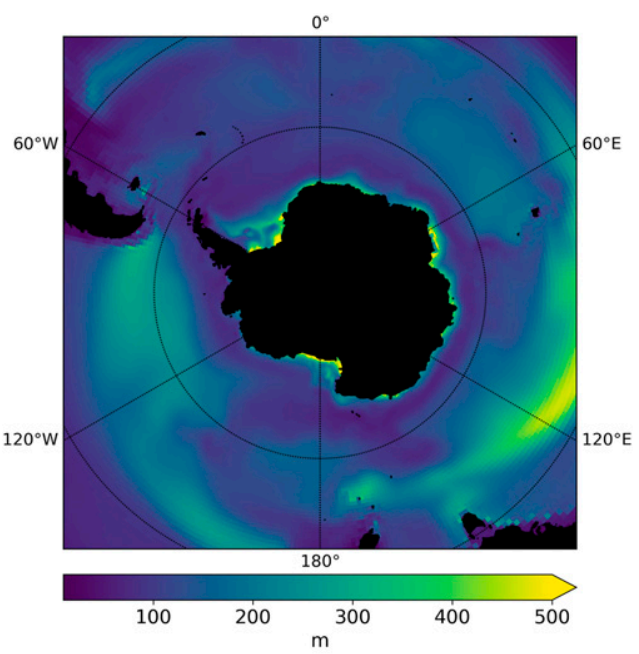

(a) PIControl

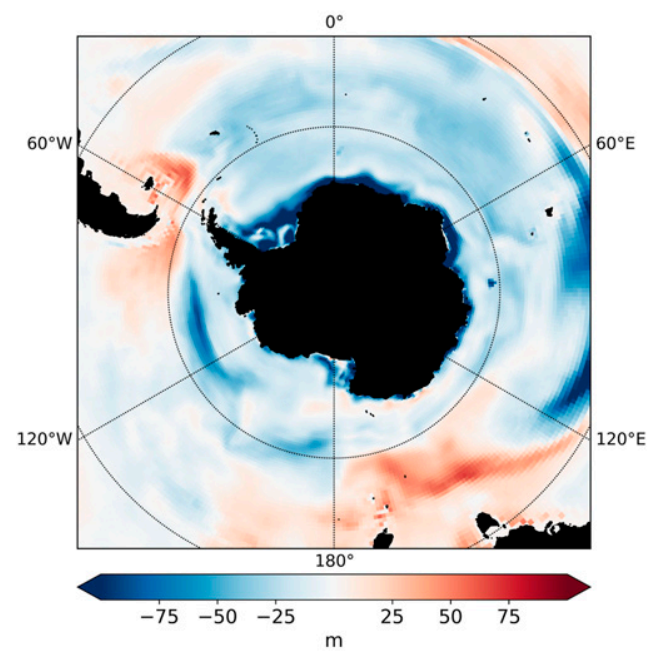

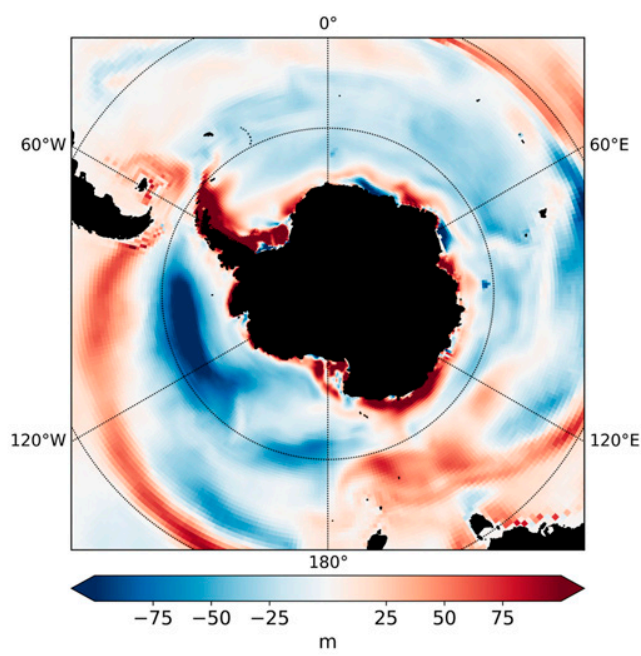

(b) FWShelf - PIControl

(c) FWBerg - PIControl

FIG. 10. (a) The mean mixed layer depth for September for PIControl, and the September anomaly averaged over the final 30 years of the experiments: (b) FWShelf and (c) FWBerg. Dotted lines mark meridians as labeled and parallels at $40^{\circ}$ and $60^{\circ} \mathrm{S}$.

and more heat is pumped from deeper ocean layers and advected toward the surface in front of the ice shelves, reducing the sea ice volume near the ice shelf margins. This encourages shore leads to form, where latent heat release generates more frazil (Fig. 8), which then increases sea ice production (Jourdain et al. 2017). In contrast, FWBerg results in a shallowing of the mixed layer around the coast, including in areas of increased sea ice production such as along the eastern Indian Ocean-western Weddell Sea coastline, and along the western coast of the Antarctic Peninsula. The large increase in surface meltwater from icebergs here stratifies the ocean, in agreement with Pauling et al. (2016), and saline rejection is too diffuse to generate large-scale circulation changes.
The dense sinking water associated with sea ice production can spill over the shelf edge into the deep ocean as AABW. The Weddell and Ross Seas and the Adélie Coast in the western Pacific are the dominant sources of $\mathrm{AABW}$ production in the real ocean (van Aken 2007; Nicholls et al. 2009). The changes to sea ice production and mixed layer depth in these regions may therefore impact on $\mathrm{AABW}$ formation. We use the northward transport of $\mathrm{AABW}$ as a proxy for its formation, and compute this by zonally integrating the meridional velocity at $3^{\circ} \mathrm{S}$ and taking the first maximum of the vertical integral (calculated upward from the sea floor) to be the transport (following Heuzé et al. 2015). We assume that any reduction (increase) in AABW formation will be reflected in a reduction 


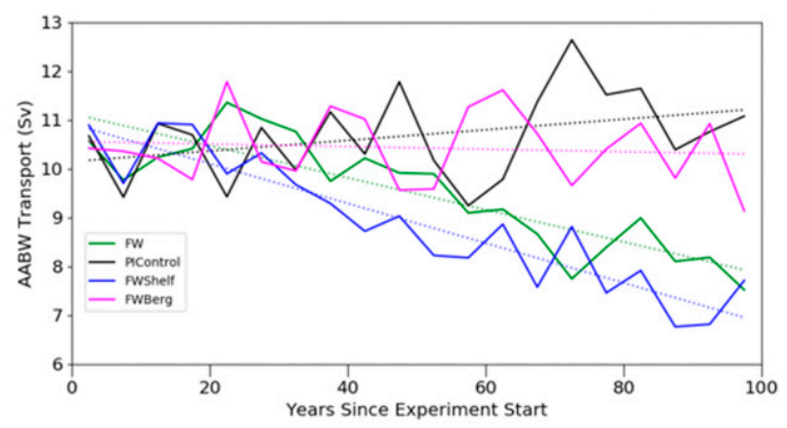

(a)

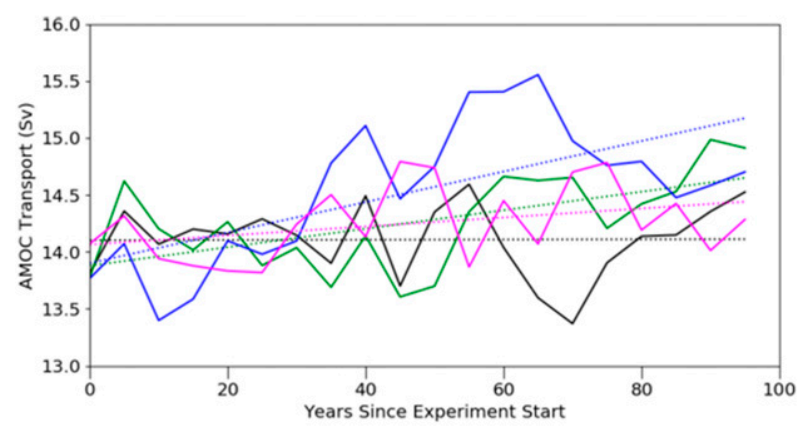

(b)

FIG. 11. (a) The zonal mean maximum AABW transport at $30^{\circ} \mathrm{S}$. (b) AMOC strength at $30^{\circ} \mathrm{S}$. The solid line is the 5-yr running mean, and the dotted line shows the linear fitted trend.

(increase) in the northward export of AABW (Fig. 11a). To assess any impact on the AMOC, we follow Heuzé et al. (2015) and define the AMOC strength as the first maximum of the depth-integrated southward meridional velocity, after first integrating across the Atlantic Ocean at $30^{\circ} \mathrm{S}$ (Fig. 11b).

Both FWShelf and FW (FW not shown) result in an overall increase in sea ice production over the continental shelf (Fig. 9b); however, this is associated with a decrease in AABW formation relative to PIControl. This reduction follows from the freshening of the whole water column over the shelf seas in response to the large additional melt flux that enters at the ice shelf fronts. This freshening can be seen in the evolution of the salinity response for the ocean south of $60^{\circ} \mathrm{S}$ for FWShelf and $\mathrm{FW}$, but not for FWBerg, where meltwater enters at the ocean surface and is more widely distributed (Fig. 12). This agrees

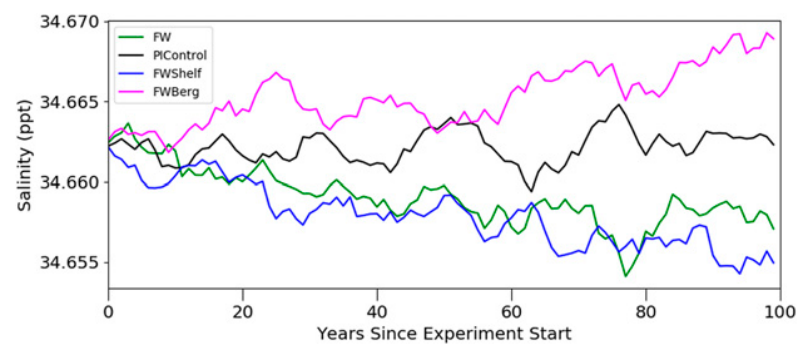

FIG. 12. Mean anomaly in depth-averaged salinity for ocean south of $60^{\circ} \mathrm{S}$ (5-yr running mean). with findings in Silvano et al. (2018) but contrasts with the findings from Lago and England (2019), who used a coupled ocean-sea ice model driven by climatological atmospheric forcing to assess the impact of Antarctic melt fluxes on AABW production. The melt fluxes in Lago and England (2019) all entered the ocean at the surface [not at depth as in FW and FWShelf here and in Silvano et al. (2018)] and induced a stratification that resulted in a decline in $\mathrm{AABW}$ formation over the continental shelf. In our study, the stratification induced by surface melt fluxes in FWBerg (Fig. 10) is not enough to reduce $\mathrm{AABW}$ formation, and we see a decline only when melt enters the ocean at depth and freshens the water column.

The impact of this reduction in AABW formation on the AMOC appears small in Fig. 11b, and so we used a Student's $t$ test to compare the experiments with PIControl for the final 20 years of the simulations. Over the final 20 years of the simulations, the AMOC has an average strength of $14.22 \mathrm{~Sv}$ in PIControl, and this is 0.43 and $0.35 \mathrm{~Sv}$ stronger in FW and FWShelf, respectively, at the $95 \%$ confidence level. There is no statistically significant change to the AMOC strength in FWBerg (the $p$ value is greater than 0.7 ).

\section{d. Surface ocean}

Sea surface temperature (SST) and salinity (SSS) respond to the increased freshwater and latent heat fluxes (Figs. 13 and 14). The SST and SSS responses were similar in winter and summer, so presented responses include data from all seasons.

Strong surface cooling and freshening of Antarctic waters is expected in all the experiments, as the meltwater remains at the surface (Fig. 16a), cooling and enhancing stratification (although Antarctic coastal waters are likely to be at, or close to, freezing and cannot be cooled further). The SST and SSS anomalies may be distributed differently in the experiments, as some of the anomaly is the direct effect of the additional melt, and some is the result of the increased sea ice volume stimulated by the additional melt. The Southern Ocean surface freshens in all experiments, but the freshening is slightly stronger in FWShelf than in FWBerg along the Antarctic coast, reflecting large ice shelf melt fluxes. Freshening is slightly stronger in FWBerg northeast of the Antarctic Peninsula, where iceberg melt is high (Fig. 2). The strongest surface cooling occurs in FWShelf, which represents the most spatially concentrated additional melt flux, and is weakest in FWBerg, where the melt is most widely distributed. Surface cooling in FW is somewhere between FWShelf and FWBerg as expected. Surface waters around New Zealand, southern Australia, South America, and the southern tip of Africa freshen in all the experiments, with a similar spatial distribution for the salinity response in FWShelf and FWBerg, although the magnitude of the anomalies is greater in FWShelf than in FWBerg. FWShelf also results in greater cooling at latitudes far from Antarctica than FWBerg, meaning that the distal effects in Figs. 13 and 14 for FW cannot be attributed to melt from far-traveling icebergs but rather are more likely to be associated with the processes discussed below. Both FWShelf and FWBerg result in stronger surface salinity anomalies in the Northern Hemisphere than are seen in FW, suggesting some interdependency of responses to the two processes. 

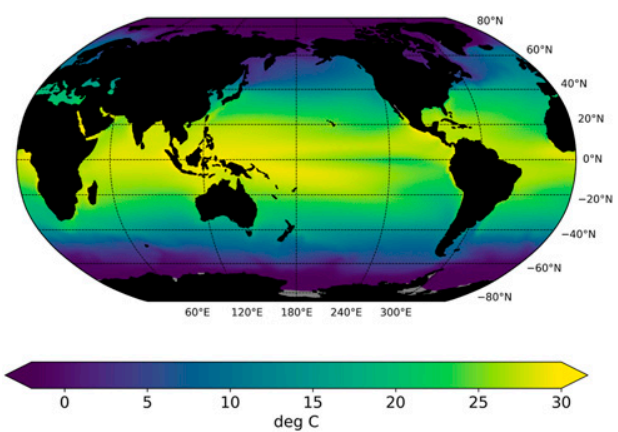

(a) PIControl

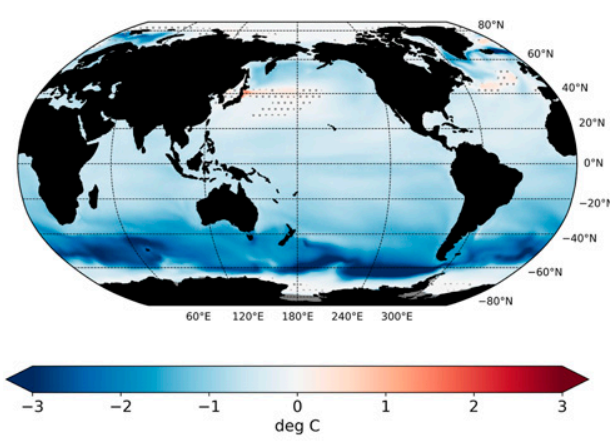

(c) FWShelf - PIControl
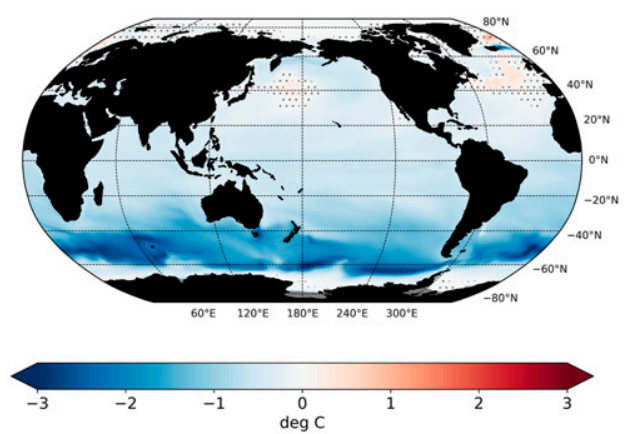

(b) FW - PIControl

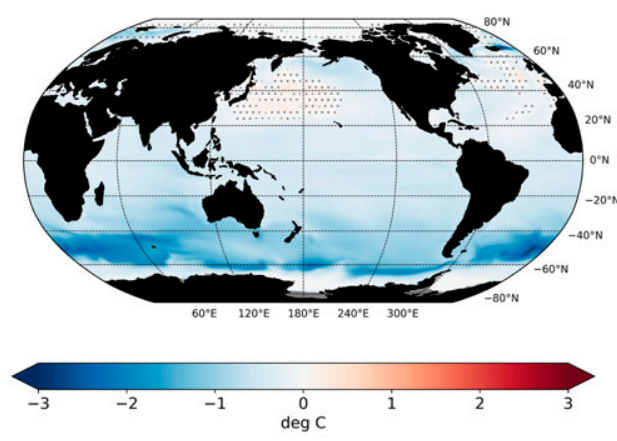

(d) FWBerg - PIControl

FIG. 13. (a) Mean SST in PIControl, and the SST anomaly, averaged over the final 30 years of each experiment: (b) FW, (c) FWShelf, and (d) FWBerg. Stippling marks anomalies that are not significant at the $95 \%$ confidence level, calculated using Student's $t$ test.

There is a strong increase in SSS in the Arctic Ocean in all the experiments, which cannot be explained by saltier water upwelling since there is no deepening of the mixed layer (Fig. S3 in the online supplemental material), or by changes to the relative river discharge rates into the different ocean basins (Fig. S4 in the online supplemental material). The SSS response here and throughout the Northern Hemisphere agrees with that in van den Berk et al. (2019), where increasing meltwater fluxes around Antarctica resulted in changes to ocean circulation that impacted on salt transport into (and out of) the Arctic Ocean over a similar time scale to our experiments, using a similar model. The mechanisms shown in that work to link an Antarctic meltwater perturbation to SSS changes in the North Atlantic are complex, and we refer the reader to van den Berk et al. (2019) for a comprehensive description. Alternative oceanic mechanisms were proposed to explain similar Northern Hemisphere anomalies in response to an Antarctic freshwater perturbation in Richardson et al. (2005). Further work using our results would be a useful verification of those studies but is beyond the scope of the present study. Nonetheless, our findings support the assertion that the effects of Antarctic meltwater fluxes on Northern Hemisphere ocean circulation are significant, possibly more so than Arctic meltwater effects since Antarctica represents a much larger freshwater source (van den Berk et al. 2019), and because the surface salinity response does not remain local to the Antarctic meltwater perturbation location (in contrast to Arctic meltwater perturbations; Stouffer et al. 2007).

\section{e. Density and temperature}

By the end of the experiments, upper ocean waters closest to the source of the melt perturbation have become less dense due to freshening, while those farther north have become more dense due to cooling [density is calculated relative to $2000 \mathrm{~m}$ using the United Nations Educational, Scientific and Cultural Organization (UNESCO) Equation of State; Jackett and McDougall 1995] (Figs. 15-17). In all of the experiments, freshening at high latitudes decreases the water density from the surface to the depth of the continental shelf. The anomaly is strongest in FWShelf and FW, where the freshening from ice shelf melt spans the depths of the ice shelf drafts, but it is also apparent in FWBerg, where iceberg melt enters the surface ocean. Although stratification is enhanced in FWBerg, convection driven by brine rejection continues to mix the iceberg melt with the underlying waters in some areas, creating the weak freshening and positive density anomaly that extends to the continental shelf depth at high latitudes.

Midlayer waters warm near the Antarctic coast in all three experiments. This is because the increased sea ice cover and 

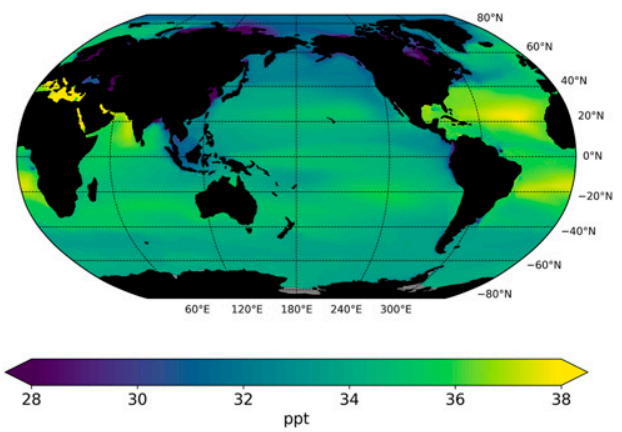

(a) PIControl

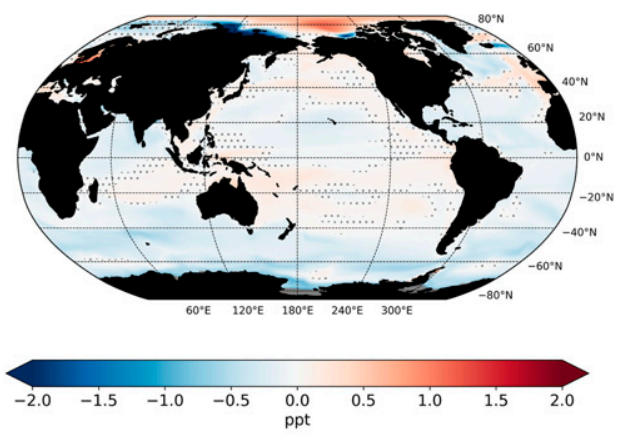

(c) FWShelf - PIControl

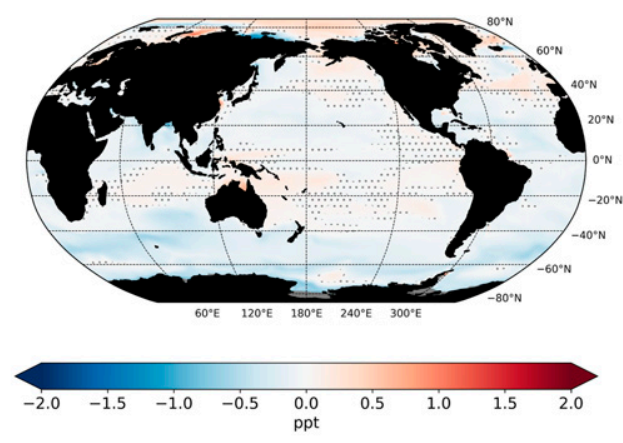

(b) FW - PIControl

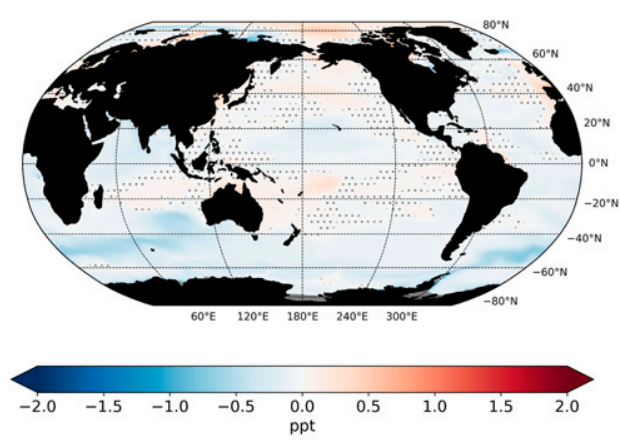

(d) FWBerg - PIControl

FIG. 14. As in Fig. 13, but for mean SSS.

the fresher, more buoyant overlying waters prevent midlayer water from rising and exchanging heat with the atmosphere. This warming is strongest in FW and FWShelf, for which the freshening of the coastal waters is strongest because of the ice shelf melt flux, and surface cooling north of the sea ice edge is strongest. In FWShelf, the warm anomaly in Fig. 15c extends north and reaches to the sea floor at midlatitudes, reflecting the

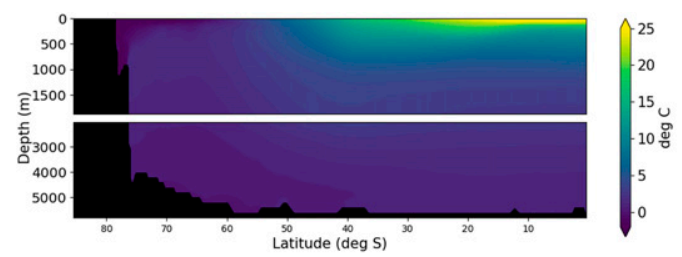

(a) PIControl

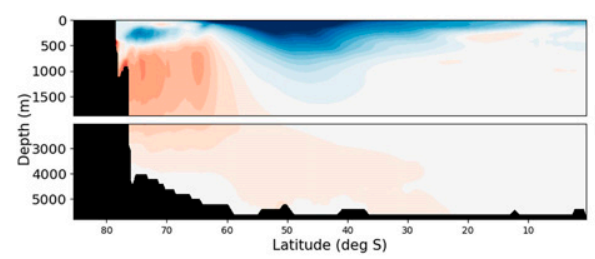

(c) FWShelf - PIControl reduction in $\mathrm{AABW}$ driven by the freshening effect of the ice shelf melt (Fig. 11). The warm signal also extends to the midlatitudes in FW (Fig. 15b), although it remains farther south and is mostly confined to the upper layers of the water affected by the warming in FWShelf. In FWBerg, where AABW is largely unchanged from PIControl (Fig. 11), the warm anomaly does not extend to the sea floor beyond the continental shelf

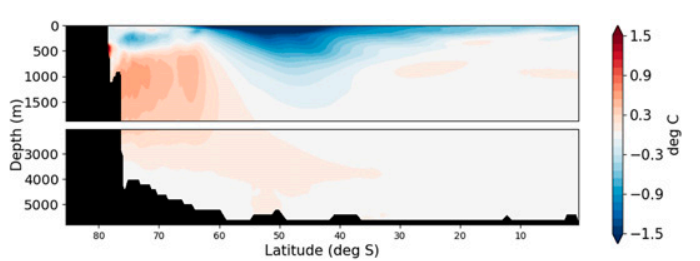

(b) FW - PIControl

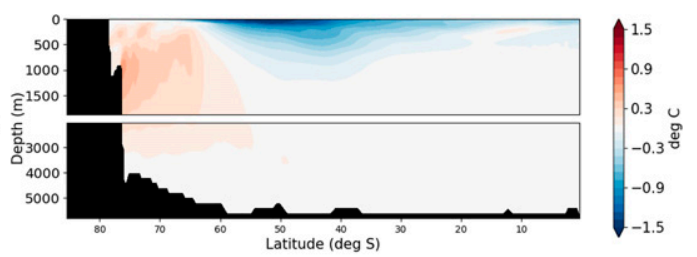

(d) FWBerg - PIControl

FIG. 15. (a) Zonal mean temperature in PIControl, and the anomaly averaged over the final 30 years of the experiments: (b) FW; (c) FWShelf; and (d) FWBerg. Note the change of scale at depth $2100 \mathrm{~m}$. 


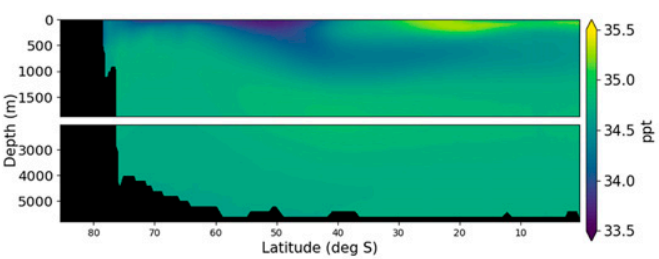

(a) PIControl

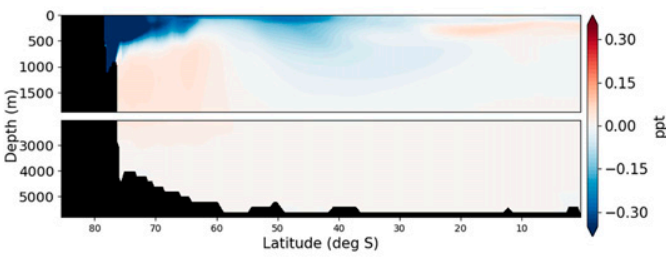

(c) FWShelf - PIControl

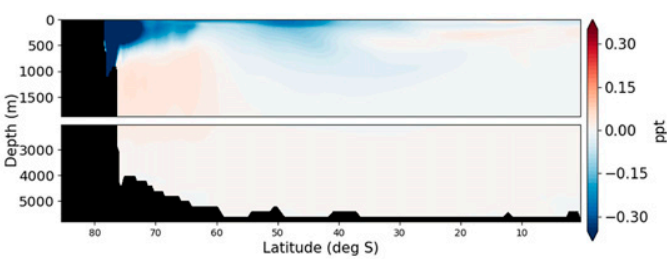

(b) FW - PIControl

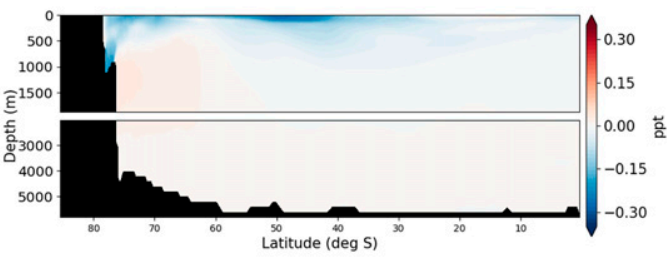

(d) FWBerg - PIControl

FIG. 16. As in Fig. 15, but for zonal mean salinity.

edge and is confined to the sea ice region (Fig. 15d). Similar warming of midlayer waters was found by Bronselaer et al. (2018), where it was explained by increased stratification that prevented these waters from mixing with surface waters and cooling as they traveled poleward. This increased the heat transported to the coast, potentially contributing to a reduction in AABW formation in that study.

In our study, the mixed layer becomes shallower north of the sea ice region in response to both ice shelf and iceberg melt (Fig. 10). If the warming of midlatitude waters were solely driven by increased stratification, then we would expect midlatitude waters in FWBerg to warm similarly to the same waters in FWShelf and FW, although more weakly since the stratification is slightly weaker (Fig. 10). However, the warming of deeper waters beyond the sea ice region occurs only in FW and FWShelf (Fig. 15), so cannot be completely driven by the increased stratification. The freshening of the water column above the continental shelf reduces AABW formation in FWShelf and FW (Fig. 11), and the warm anomaly that spreads down to the shelf and over the shelf edge in Figs. 15b and $15 \mathrm{c}$ is due to reduced cold AABW production in FWShelf and FW, compared to PIControl. AABW formation in FWBerg is similar to PIControl (Fig. 11), and therefore there is no deeper warm anomaly in FWBerg, relative to PIControl. The reduction in AABW production in FWShelf and FW creates a warm anomaly in deeper midlatitude waters, which may then allow for increased heat transport to the coast, further reducing AABW formation.

Surface cooling becomes stronger north of the sea ice edge in all the experiments. The cooling, and the resultant density increase, are confined to increasingly shallow depths as the signal extends north. The cooling and density increase of upper ocean waters far from the coast is weakest in FWBerg, despite melt in this experiment being distributed over the widest range of latitudes. This may be because the local changes to ocean volume and salinity that are responsible for the ocean circulation effects identified in van den Berk et al. (2019) (see section 3) are stronger in FWShelf, where the increasing

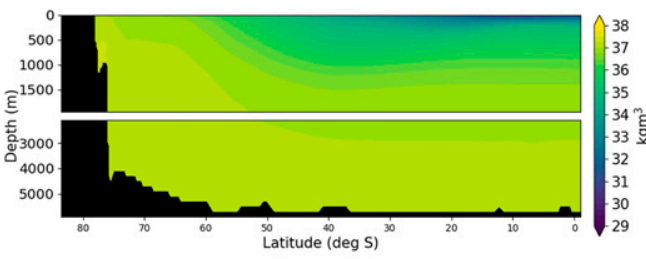

(a) PIControl

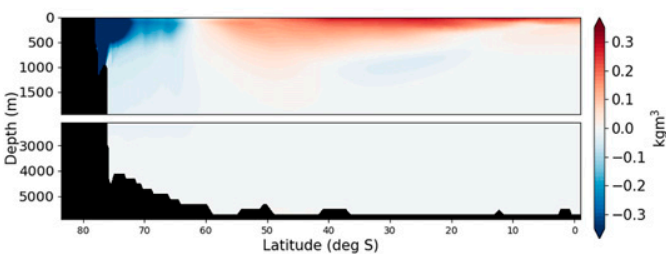

(c) FWShelf - PIControl

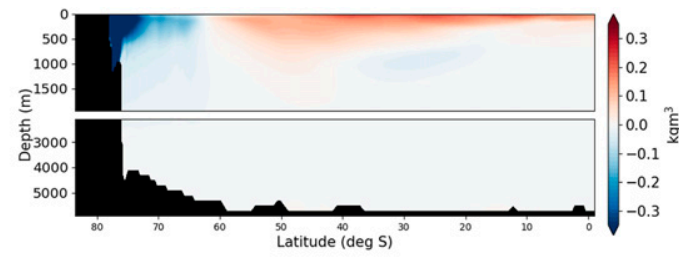

(b) FW - PIControl

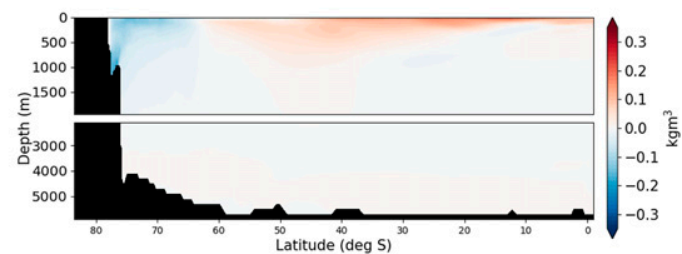

(d) FWBerg - PIControl

FIG. 17. As in Fig. 15, but for zonal mean density. 


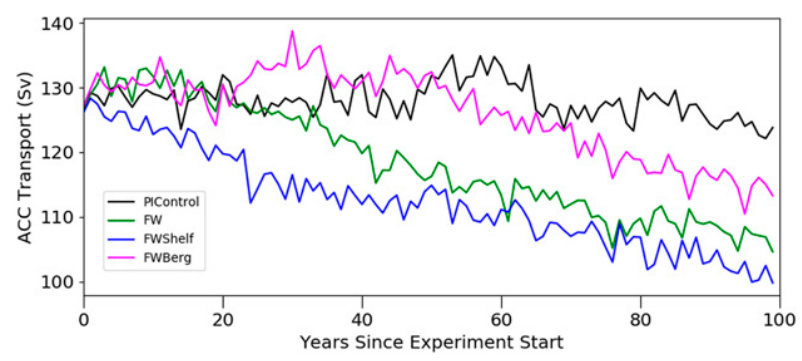

FIG. 18. Annual mean ACC transport, calculated as integrated mass transport across the Drake Passage.

freshwater flux is more spatially concentrated. For all the experiments, the high-latitude decrease in surface density is greater than the lower-latitude increase, reflecting a reduction in the meridional density gradient that could impact on the Antarctic Circumpolar Current (ACC) (Russell et al. 2006).

\section{f. $A C C$}

The ACC is a central component of global ocean circulation, linking the subtropical and subpolar gyres and providing a barrier to heat transport from lower latitudes to the polar region. It weakens over the course of all the experiments following the decreased meridional density gradient (Fig. 18).

Following Russell et al. (2006), we consider both the ACC and the difference in the upper ocean density between $65^{\circ}$ and $45^{\circ} \mathrm{S}$ that is associated with the eastward geostrophic flow, to confirm that the ACC declines as the meridional density difference reduces (Fig. 19). The greatest reduction in the ACC, and the closest relationship between this and the density difference, occurs in FWShelf, where the density gradient has experienced the greatest decrease. To determine whether salinity or temperature provide the primary driver for the density gradient changes, we again follow Russell et al. (2006) and consider the evolution of the difference in zonally averaged upper ocean density, temperature and salinity at the two latitudes (Fig. 20). The density difference closely follows the temperature difference (rather than the salinity difference) in all the experiments (only FW shown).

An increasing melt flux entering Antarctic coastal waters reduces the meridional density gradient across the Southern Ocean by impacting on near-surface temperature, and, to a lesser extent, on near-surface salinity. This causes a reduction in ACC transport. The ACC is much less sensitive to iceberg melt, which enters the ocean distributed across a wider range of latitudes, than to melt from ice shelves.

\section{g. Wind stress}

The cold atmosphere at high latitudes creates a meridional gradient in the surface heat flux (the heat exchanged between the ocean and atmosphere), which is one factor that drives the westerly jet associated with the SAM (Kidston et al. 2011). In the experiments, cooler surface temperatures and increased sea ice cover reduce the surface heat flux, and so potentially impact the jet, particularly in winter, when the sea ice extends farther north and the changes to the surface heat flux therefore occur closer to the jet's peak (the jet is more sensitive to changes in the vicinity of the peak wind; Kidston et al. 2011). In our experiments, this results in August, September, October being the period with the strongest wind response, in agreement with other studies (Kidston et al. 2011; Bader et al. 2013; Grise and Polvani 2016) (the maximum sea ice extent occurs in September; Fig. 3). We define the maximum zonally averaged westerly wind stress on the ocean surface as a proxy for the jet strength and take the latitude at which this occurs as the jet position (Fig. 21).

Changes to the peak wind strength and position may be small relative to the model grid resolution, and so the peak wind strength and position were read from a curve fitted

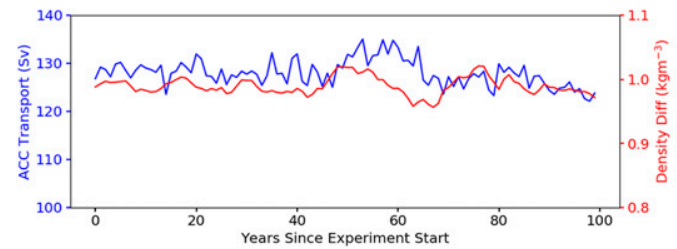

(a) PIControl

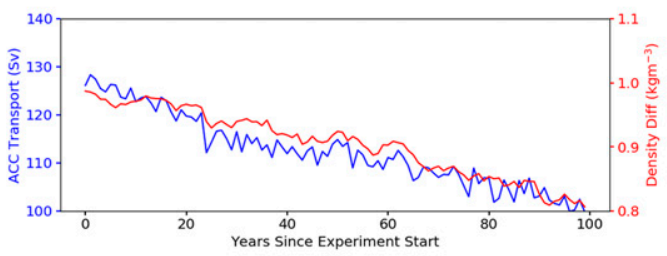

(c) FWShelf

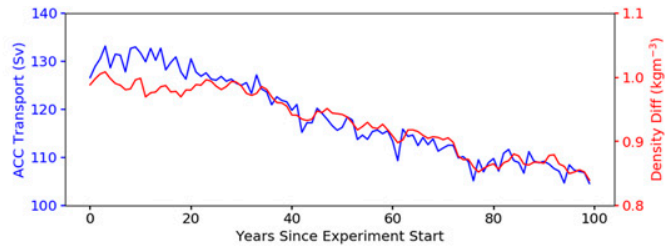

(b) FW

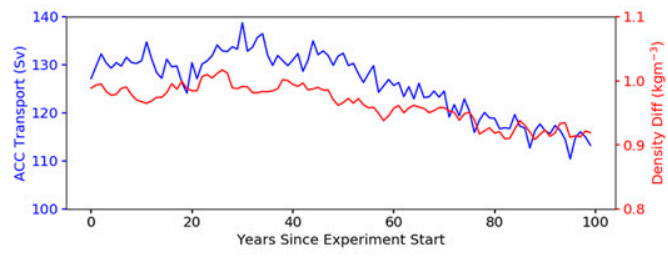

(d) FWBerg

FIG. 19. The ACC (blue), and the difference in the zonally and depth-averaged (0-1500 $\mathrm{m})$ density between $45^{\circ}$ and $65^{\circ} \mathrm{S}$ (red) for (a) PIControl, (b) FW, (c) FWShelf, and (d) FWBerg. 


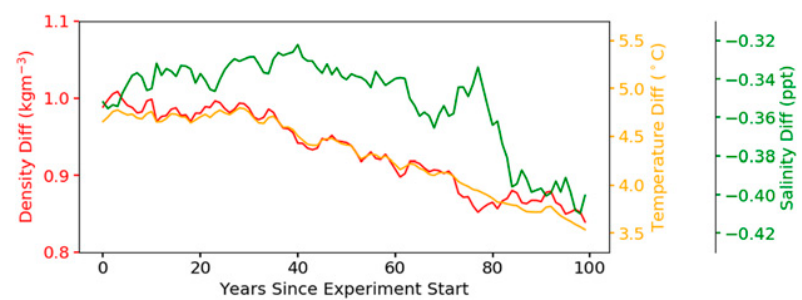

FIG. 20. The difference in the zonally and depth-averaged (0$1500 \mathrm{~m}$ ) density (red), temperature (orange), and salinity (green) between $45^{\circ}$ and $65^{\circ} \mathrm{S}$ for $\mathrm{FW}$.

around the three grid points centered on the maximum wind stress in Fig. 21. Figure 22 shows the evolution of the peak strength through the simulations. The peak position and strength for the experiments were compared to those for PIControl over the final 20 years of each simulation using a Student's $t$ test to assess the significance of any change to the mean (Table 2). We found no change to the latitude of the peak wind stress, in agreement with Bracegirdle et al. (2018), who found no strong relationship between sea ice area and jet location. There was a small change in the strength of the peak wind stress by the end of FW $\left(0.019 \mathrm{~N} \mathrm{~m}^{-2}\right)$, significant at the $95 \%$ confidence level, and a similar change $\left(0.016 \mathrm{~N} \mathrm{~m}^{-2}\right)$ by the end of FWShelf, significant at the $90 \%$ confidence level. There was no significant change in wind strength by the end of FWBerg. The changes in strength are small but suggest that the westerly winds may strengthen in response to increased sea ice cover, supporting the relationship between sea ice area and jet strength suggested in other works, for example, Menéndez et al. (1999), Kidston et al. (2011), Bader et al. (2013), Grise and Polvani (2016), and Bracegirdle et al. (2018). However, the fact that there is no significant strengthening in FWBerg, which corresponds to only slightly smaller changes in sea ice cover

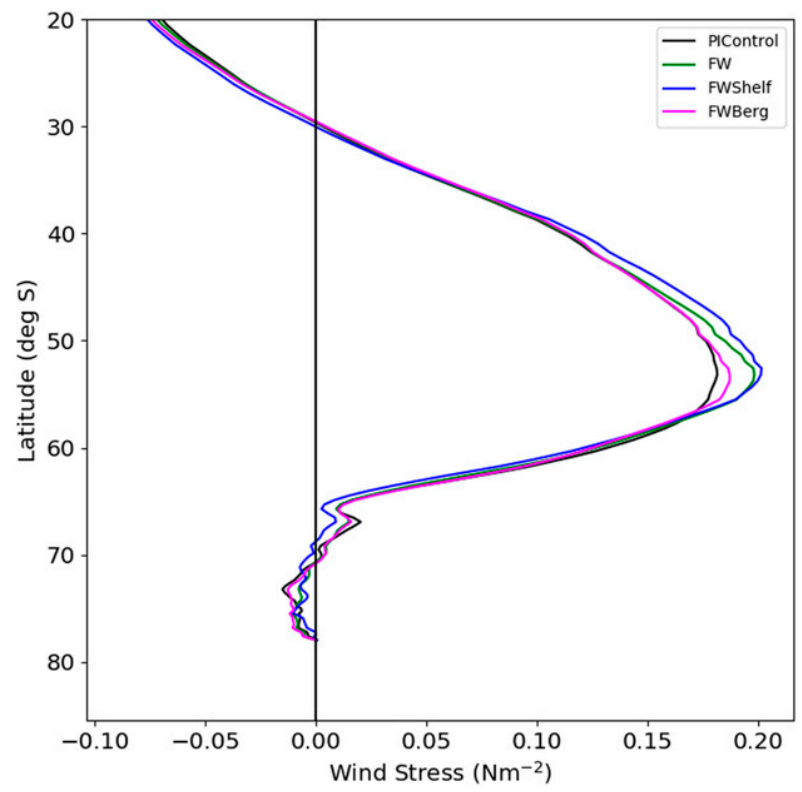

FIG. 21. Zonal mean westerly wind stress for August-October, averaged over the final 30 years of the experiments.

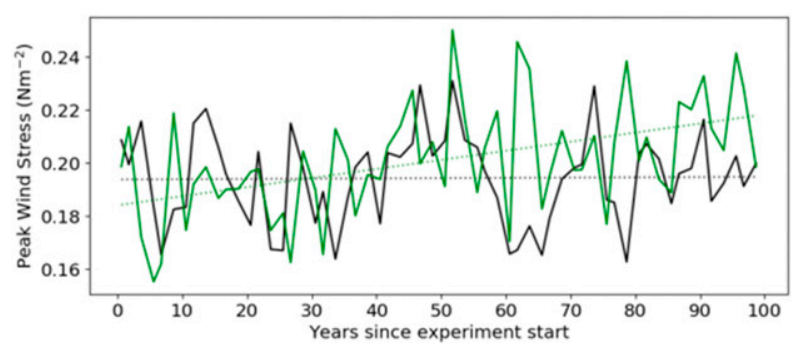

(a)

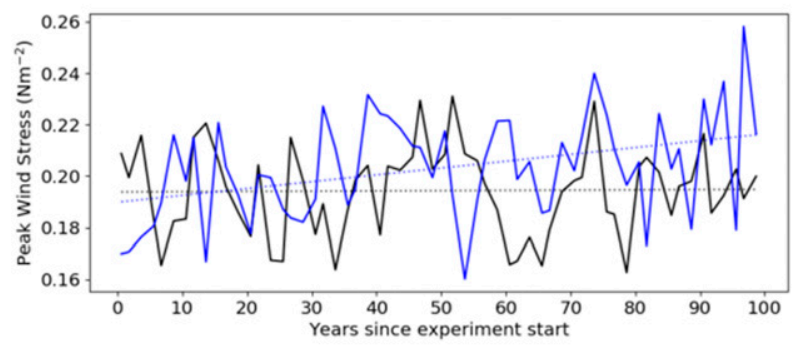

(b)

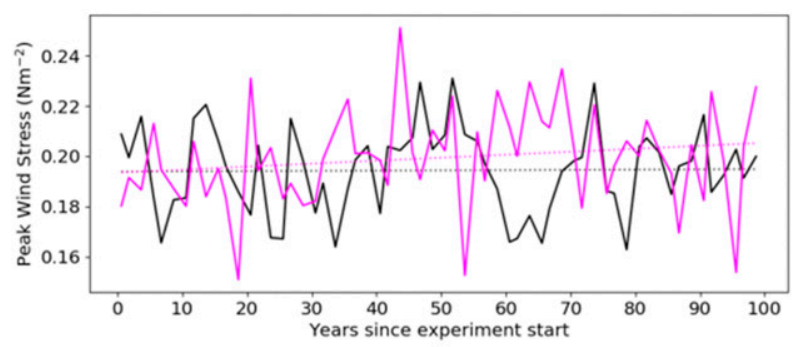

(c)

FIG. 22. Strength of the peak westerly wind stress for August, September, and October for the experiments (a) FW, (b) FWShelf, and (c) FWBerg. The colored lines show the experiments, and the black lines show PIControl. Solid lines are the 5-yr running means, and dotted lines are linear fitted trends. The model spatial resolution is fairly coarse, and the strength here follows from a quadratic curve that was fitted over the three model grid latitudes around the peak in Fig. 21.

than FW and FWShelf (Figs. 7), suggests that either a very large increase in sea ice area is required to impact the westerly winds, or that some other response to ice shelf melt (but not to iceberg melt) drives the wind response. Surface cooling at high latitudes impacts the surface heat flux similarly to sea ice cover, and so drives a similar wind response. The surface cooling at the latitudes surrounding the peak wind stress (approximately $45^{\circ}-55^{\circ} \mathrm{S}$; Fig. 21) is much greater in FW and FWShelf than in FWBerg (Fig. 13), and so results in a strengthening of the wind that is absent in FWBerg. The westerly jet extends into the atmosphere and is subject to other atmospheric effects that may impact on the stress experienced at the surface. Such 
TABLE 2. Difference between the mean wind stress for each experiment and PIControl for the final 20 years of the simulations. The significance of any change is given by the $p$ value (following from calculation of the $t$ score for related samples). A $p$ value of less than 0.05 indicates a change that is significant at the $95 \%$ confidence level (marked by boldface type).

\begin{tabular}{lrccc}
\hline \hline Expt & $\Delta$ lat $\left(^{\circ}\right)$ & $p$ value & $\Delta$ strength $\left(\mathrm{N} \mathrm{m}^{-2}\right)$ & $p$ value \\
\hline FW & -1.045 & 0.379 & $\mathbf{0 . 0 1 9}$ & $\mathbf{0 . 0 1 1}$ \\
FWShelf & 0.459 & 0.444 & 0.016 & 0.070 \\
FWBerg & -0.208 & 0.929 & 0.004 & 0.943 \\
\hline
\end{tabular}

effects may be stronger than the effect of sea ice and surface temperature changes, and further work to analyze these, and the influence of the increasing meltwater on them, is needed but is beyond the scope of this work.

\section{h. Precipitation}

Precipitation minus evaporation $(P-E)$ is the greatest freshwater contribution to the ocean south of $50^{\circ} \mathrm{S}$ (Fig. S5 in the online supplemental material). In the model, rainfall onto sea ice is assumed to run off, but snowfall onto sea ice is transported northward to where the sea ice melts. An increase in sea ice area reduces the amount of precipitation reaching the ocean (Fig. 23a). The decrease is greater than the reduction in evaporation, and so $P-E$ decreases (Fig. 23b). This salinification opposes the freshening effect of the increasing meltwater fluxes at high latitudes but does not extend beyond the latitudes of increased sea ice cover (not shown).

Increased sea ice cover and ocean stratification insulate the surface ocean, reducing the surface heat flux and cooling the lower atmosphere, making precipitation more likely to be snow, and reducing evaporation. Snow melts on entering the ocean, absorbing latent heat to cool the ocean in a way that rain does not. Although the total snowfall entering the ocean does not increase in the experiments, there is a northward shift of the polar front (the boundary between the air masses of the polar cell and the Ferrel cell), where the dominant form of precipitation switches between snow and rain (Fig. 23c). This means that the cooling effect of snow on the surface ocean has shifted northward in response to the increased melt fluxes, enhancing the surface cooling that is driven directly by the increased freshwater flux (Fig. 13). Previous studies have also shown that a freshwater perturbation at high southern latitudes shifts the intertropical convergence zone (ITCZ) northward, resulting in shifted tropical precipitation patterns (Bronselaer et al. 2018). This mainly follows from the cooling in the Southern Hemisphere, which drives a compensating increase in the southward atmospheric heat flux, and results from all our experiments concur with this (Fig. 24) (only the anomaly from FW is shown).

\section{Summary and discussion}

Antarctic sea ice expands and thickens in response to an increasing meltwater flux, with regional variations in the response that are mostly explained by the transport of meltwater and icebergs by ocean circulation. The response to increasing ice shelf melt is faster and stronger than that for increasing iceberg melt because all meltwater enters the ocean within the sea ice formation region, but otherwise the sea ice response is similar for increasing meltwater fluxes from both sources (notwithstanding regional differences attributable to the accessibility of some areas to icebergs). This agrees with previous studies (e.g., Pauling et al. 2016); however, here we have identified which sea ice growth processes are enhanced by the increasing freshwater input and assessed the sensitivities of these to the different meltwater sources. We find that sea ice growth is enhanced by surface cooling that inhibits basal melt,

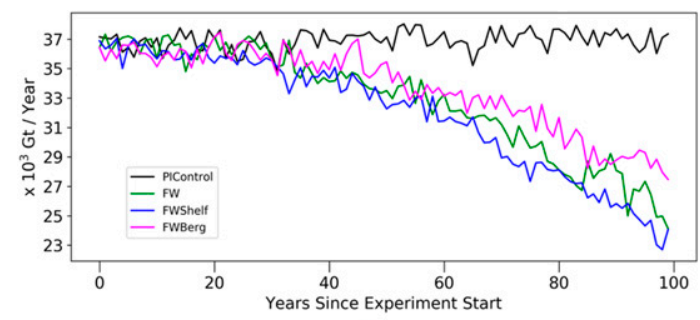

(a)

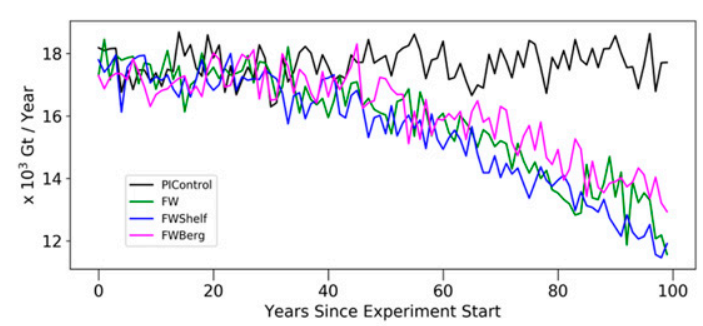

(b)

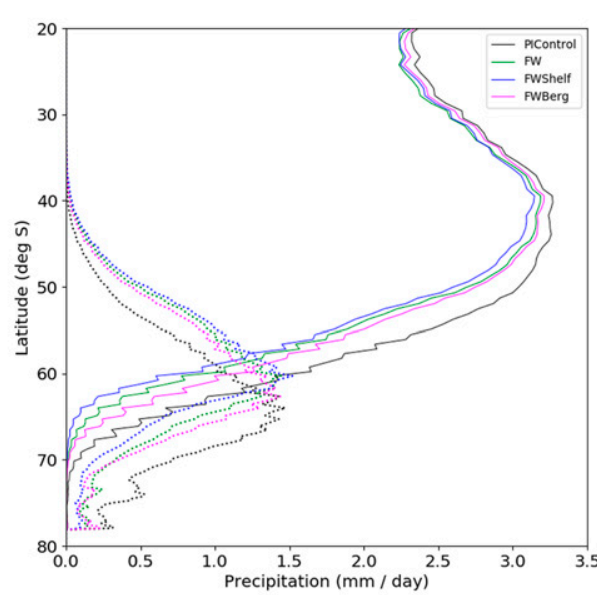

(c)

FIG. 23. (a) Mean annual precipitation (rain + snow) received by the ocean, south of $50^{\circ} \mathrm{S}$. (b) Mean annual precipitation minus evaporation over the ocean, south of $50^{\circ} \mathrm{S}$. (c) Zonal mean rainfall (solid) and snowfall (dotted) received by the ocean, averaged over the final 30 years of the experiments. 

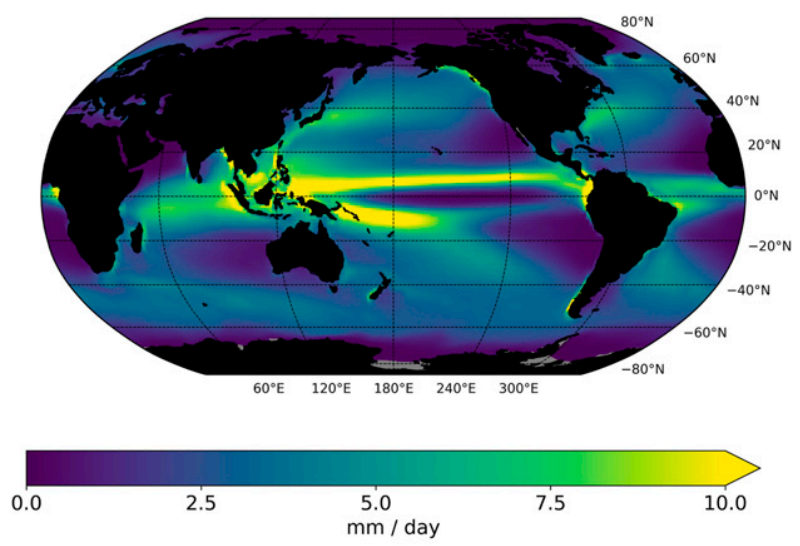

(a) PIControl
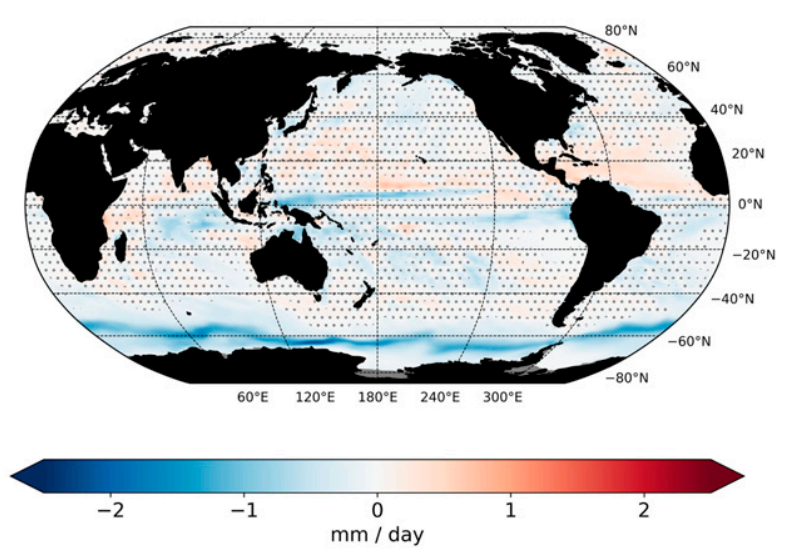

(b) FW - PIControl

FIG. 24. (a) Annual mean precipitation entering the ocean in PIControl. (b) The anomaly over the final 30 years of FW. Stippling marks anomalies that are not significant at the $90 \%$ confidence level, calculated using Student's $t$ test.

and as the ice thickens in response to this, the basal temperature becomes less conducive to congelation growth, and so frazil growth accounts for a greater proportion of total sea ice growth. Ice shelf melt entering the ocean at depth constitutes a source of supercooling, increasing frazil production, which becomes the dominant mechanism for sea ice growth when ice shelf melt is present. While we find that meltwater from both ice shelves and icebergs drives a similar increase in sea ice growth, the effect of iceberg melt is to enhance stratification in agreement with Pauling et al. (2016). Our results show that as ice shelf melt increases, the rising buoyant meltwater drives a local overturning that deepens the mixed layer. This response to increasing ice shelf melt encourages the formation of shore leads, as shown by Jourdain et al. (2017) and Merino et al. (2018). We show that the response to iceberg melt contrasts with this as the increased stratification drives in situ freezing of sea ice at the coast. We have also shown that the increased stratification induced by iceberg melt can counter increases in AABW formation that may ordinarily be associated with increased sea ice formation. Our results show that the reduction in AABW formation that follows from large ice shelf meltwater fluxes is the result of a different process, that is, the freshening of the water column. This demonstrates circumstances where increased sea ice production does not lead to increased AABW formation. AABW is a driver for the thermohaline circulation (Marsland et al. 2007), and inappropriate representation of formation rates through inappropriate representation of meltwater fluxes is therefore likely to result in an unrealistic representation of the thermohaline circulation, and therefore also of global oceanic heat transport and its response to climate change.

The ocean surface cools and midlayer waters warm in response to increases in both ice shelf and iceberg melt, in agreement with Pauling et al. (2016) and Bronselaer et al. (2018); however, our results show that the warming response extends farther north and to greater depths for increasing ice shelf melt. We find near-surface density changes that agree with the response to Antarctic meltwater-induced circulation changes in van den Berk et al. (2019), even far from the perturbation source, and we show that these changes are more sensitive to increased, concentrated meltwater anomalies at depth than to distributed melt at the surface. We demonstrate that, as a more concentrated meltwater source, increasing ice shelf melt has a greater impact on the meridional density gradient than increasing iceberg melt, and therefore drives a more severe decrease in ACC transport. These differences highlight the importance of appropriately representing these two separate melt pathways in climate studies to ensure that projections capture the likely future climate.

We find a small strengthening of the westerly circumpolar winds in response to the increased meltwater fluxes in agreement with Menéndez et al. (1999), Kidston et al. (2011), Bader et al. (2013), Grise and Polvani (2016), and Bracegirdle et al. (2018). However, in contrast to most previous works, we suggest this may be partially driven by cooling of the ocean surface, in addition to the increased sea ice extent. We found no change to the latitude of the peak wind strength, in agreement with Bracegirdle et al. (2018). As shown in previous studies (e.g., Bronselaer et al. 2018), we find increasing the rate at which Antarctic meltwater fluxes enter the Southern Ocean causes the meteorological polar front to shift northward, meaning that latent heat cooling from snowfall affects the ocean at lower latitudes and the ITCZ shifts north. Our results include significant effects on ocean SST and SSS that extend into the Northern Hemisphere and cannot be explained by fartraveling icebergs. Neglecting the increasing melt rate of Antarctica could therefore have implications for projections of Northern Hemisphere climate. Some research into the mechanisms that drive these distal effects exists (Richardson et al. 2005; Stouffer et al. 2007; van den Berk et al. 2019), but more is needed so that we can understand the implications of increasing Antarctic meltwater fluxes for the wider Northern Hemisphere climate system.

The model used here includes improvements to the representation of ice shelf and iceberg meltwater fluxes in a fully 
coupled climate model, relative to CMIP5-generation models, but there remain some simplifications that may impact on the presented sensitivities. For example, small icebergs account for most of the iceberg meltwater flux into the Southern Ocean (Tournadre et al. 2015), but larger icebergs do occur, and these follow different trajectories, persist for longer and melt with less seasonal dependence (since their keels extend into deeper ocean layers where seasonal temperature variability is less), creating temporally and spatially local peaks in the iceberg meltwater flux that are not captured in HadGEM3-GC3.1 (Rackow et al. 2017). In particular, larger icebergs may persist for longer in the Antarctic coastal current and provide a more persistent, distributed meltwater source at the coast than simulated in our study (Silva et al. 2006; Rackow et al. 2017). Icebergs extend below the ocean surface and interact with subsurface ocean currents, meaning their trajectories, and the spatial distribution of the melt-induced cooling effect, may differ from our simulations. Similarly, iceberg melt rates may not always be realistically represented in HadGEM3-GC3.1, since water temperature at the iceberg base is unlikely to always differ from the surface temperature by $4^{\circ} \mathrm{C}$ (although most melt from icebergs surrounded by ocean is attributable to wave erosion rather than to basal melt; Marsh et al. 2015). Improvements to iceberg representation have been implemented in stand-alone and coupled ocean-sea ice models, allowing for large tabular icebergs and for dynamic coupling with subsurface ocean properties (Merino et al. 2016; Stern et al. 2017; Marson et al. 2018). Including these developments in future fully coupled (atmosphere-ocean-sea ice) climate models will make simulated iceberg meltwater fluxes more realistic. Representing open ice shelf cavities in a coupled climate model remains a challenge; however, the new parameterization implemented here approximates the cavity more realistically than was previously possible in coupled climate models (Mathiot et al. 2017), and the resulting meltwater distribution is thought to be realistic, giving us confidence in the presented sensitivities. For this sensitivity study, all other external forcings were fixed at preindustrial levels; however, some of the responses presented here may be countered by the effects of increasing greenhouse gas emissions in a more realistic environment, and this is an active area of research (Mackie et al. 2020b). Future model development will allow dynamic coupling of an ice sheet model to the climate model. The sensitivities found here demonstrate the importance of that work, which will allow climate projections to be calculated accounting for realistically increasing meltwater fluxes from ice shelves and icebergs. Current climate projections that do not account for increasing Antarctic melt rates, or for separate iceberg and ice shelf melt sources and their different effects, should be interpreted in light of the sensitivities presented here.

Acknowledgments. This work was funded by New Zealand Deep South National Science Challenge, MBIE Contract $\mathrm{C} 01 \times 142$. Data for PIControl were calculated by the Met Office Hadley Centre for submission to the CMIP6 experiment. The project is grateful for support from Professor Bitz at the University of Washington. We acknowledge use of the Monsoon2 system, and the High Capacity Storage Service at
University of Otago, New Zealand. Model data analyzed in this work are publicly available in Mackie et al. (2020a).

\section{REFERENCES}

Bader, J., M. Flügge, N. G. Kvamst $\varnothing$, M. D. S. Mesquita, and A. Voigt, 2013: Atmospheric winter response to a projected future Antarctic sea-ice reduction: A dynamical analysis. Climate Dyn., 40, 27072718, https://doi.org/10.1007/s00382-012-1507-9.

Bigg, G. R., M. R. Wadley, D. P. Stevens, and J. A. Johnson, 1997: Modelling the dynamics and thermodynamics of icebergs. Cold Reg. Sci. Technol., 26, 113-135, https://doi.org/10.1016/ S0165-232X(97)00012-8.

Bintanja, R., G. J. van Oldenborgh, S. S. Drijfhout, B. Wouters, and C. A. Katsman, 2013: Important role for ocean warming and increased ice-shelf melt in Antarctic sea-ice expansion. Nat. Geosci., 6, 376-379, https://doi.org/10.1038/ngeo1767.

$\longrightarrow,-$, and C. Katsman, 2015: The effect of increased fresh water from Antarctic ice shelves on future trends in Antarctic sea ice. Ann. Glaciol., 56, 120-126, https://doi.org/10.3189/2015AoG69A001.

Bracegirdle, T. J., E. Shuckburgh, J.-B. Sallee, Z. Wang, A. J. S. Meijers, N. Bruneau, T. Phillips, and L. J. Wilcox, 2013: Assessment of surface winds over the Atlantic, Indian, and Pacific Ocean sectors of the Southern Ocean in CMIP5 models: Historical bias, forcing response, and state dependence. J. Geophys. Res. Atmos., 118, 547-562, https://doi.org/ 10.1002/JGRD.50153.

— , P. Hyder, and C. R. Holmes, 2018: CMIP5 diversity in southern westerly jet projections related to historical sea ice area: Strong link to strengthening and weak link to shift. J. Climate, 31, 195-211, https://doi.org/10.1175/JCLI-D-17-0320.1.

Bronselaer, B., M. Winton, S. M. Griffies, W. J. Hurlin, K. B. Rodgers, O. V. Sergienko, R. J. Stouffer, and J. L. Russell, 2018: Change in future climate due to Antarctic meltwater. Nature, 564, 53-58, https://doi.org/10.1038/s41586-018-0712-z.

Buckley, M. W., and J. Marshall, 2016: Observations, inferences, and mechanisms of the Atlantic meridional overturning circulation: A review. Rev. Geophys., 54, 5-63, https://doi.org/ 10.1002/2015RG000493.

Cavalieri, D. J., and C. L. Parkinson, 2008: Antarctic sea ice variability and trends, 1979-2006. J. Geophys. Res. Oceans, 113, C07004, https://doi.org/10.1029/2007JC004564.

Comiso, J. C., R. Kwok, S. Martin, and A. L. Gordon, 2011: Variability and trends in sea ice extent and ice production in the Ross Sea. J. Geophys. Res., 116, C04021, https://doi.org/ 10.1029/2010JC006391.

DeConto, R. M., and D. Pollard, 2016: Contribution of Antarctica to past and future sea-level rise. Nature, 531, 591-597, https:// doi.org/10.1038/nature17145.

Depoorter, M. A., J. L. Bamber, J. A. Griggs, J. T. M. Lenaerts, S. R. M. Ligtenberg, M. R. van den Broeke, and G. Moholdt, 2013: Calving fluxes and basal melt rates of Antarctic ice shelves. Nature, 502, 89-92, https://doi.org/10.1038/nature12567.

Grise, K. M., and L. M. Polvani, 2016: Is climate sensitivity related to dynamical sensitivity? J. Geophys. Res. Atmos., 121, 51595176, https://doi.org/10.1002/2015JD024687.

Hellmer, H. H., 2004: Impact of Antarctic ice shelf basal melting on sea ice and deep ocean properties. Geophys. Res. Lett., 31, L10307, https://doi.org/10.1029/2004GL019506.

Heuzé, C., K. J. Heywood, D. P. Stevens, and J. K. Ridley, 2015: Changes in global ocean bottom properties and volume transports in CMIP5 models under climate change scenarios. J. Climate, 28 , 2917-2944, https://doi.org/10.1175/JCLI-D-14-00381.1. 
Hoskins, B. J., and K. I. Hodges, 2005: A new perspective on Southern Hemisphere storm tracks. J. Climate, 18, 4108-4129, https://doi.org/10.1175/JCLI3570.1.

Hunke, E. C., W. H. Lipscomb, A. K. Turner, N. Jeffrey, and S. Elliott, 2015: CICE: The Los Alamos Sea Ice Model documentation and software user's manual, version 5.1. Doc. LA-CC06-012, 116 pp., http://www.ccpo.odu.edu/ klinck/Reprints/ PDF/cicedoc2015.pdf.

Jackett, D. R., and T. J. McDougall, 1995: Minimal adjustment of hydrographic profiles to achieve static stability. J. Atmos. Oceanic Technol., 12, 381-389, https://doi.org/10.1175/15200426(1995)012<0381:MAOHPT>2.0.CO;2.

Jourdain, N. C., P. Mathiot, N. Merino, G. Durand, J. Le Sommer, P. Spence, P. Dutrieux, and G. Madec, 2017: Ocean circulation and sea-ice thinning induced by melting ice shelves in the Amundsen Sea. J. Geophys. Res. Oceans, 122, 2550-2573, https://doi.org/10.1002/2016JC012509.

Kidston, J., A. S. Taschetto, D. W. J. Thompson, and M. H. England, 2011: The influence of Southern Hemisphere sea-ice extent on the latitude of the mid-latitude jet stream. Geophys. Res. Lett., 38, L15804, https://doi.org/10.1029/2011GL048056.

Kuhlbrodt, T., and Coauthors, 2018: The low-resolution version of HadGEM3 GC3.1: Development and evaluation for global climate. J. Adv. Model. Earth Syst., 10, 2865-2888, https:// doi.org/10.1029/2018MS001370.

Lago, V., and M. H. England, 2019: Projected slowdown of Antarctic bottom water formation in response to amplified meltwater contributions. J. Climate, 32, 6319-6335, https:// doi.org/10.1175/JCLI-D-18-0622.1.

Langhorne, P. J., and Coauthors, 2015: Observed platelet ice distributions in Antarctic sea ice: An index for ocean-ice shelf heat flux. Geophys. Res. Lett., 42, 5442-5451, https://doi.org/ 10.1002/2015GL064508.

Le Quéré, C., and Coauthors, 2007: Saturation of the Southern Ocean $\mathrm{CO}_{2}$ sink due to recent climate change. Science, 316, 1735-1738, https://doi.org/10.1126/science.1136188.

Liston, G. E., and J.-G. Winther, 2005: Antarctic surface and subsurface snow and ice melt fluxes. J. Climate, 18, 1469-1481, https://doi.org/10.1175/JCLI3344.1.

Losch, M., 2008: Modeling ice shelf cavities in a z coordinate ocean general circulation model. J. Geophys. Res., 113, C08043, https://doi.org/10.1029/2007JC004368.

Mackie, S., I. J. Smith, J. K. Ridley, D. P. Stevens, and P. J. Langhorne, 2020a: Climate model response to increasing Antarctic iceberg and ice shelf melt. PANGAEA, accessed 9 September 2020, https://doi.org/10.1594/PANGAEA.911392.

$\longrightarrow,-$ D. P. Stevens, J. K. Ridley, and P. J. Langhorne, 2020b: Interactions between increasing $\mathrm{CO}_{2}$ and Antarctic melt rates. J. Climate, 33, 8939-8956, https://doi.org/10.1175/JCLI-D-190882.1.

Madec, G., and the NEMO Team, 2016: NEMO ocean engine, version 3.6 stable. Note du Pôle de modelisation de l'Institut Pierre-Simon Laplace 27, 396 pp., https://www.nemo-ocean.eu/ wp-content/uploads/NEMO_book.pdf.

Marsh, R., and Coauthors, 2015: NEMO-ICB (v1.0): Interactive icebergs in the NEMO ocean model globally configured at eddy-permitting resolution. Geosci. Model Dev., 8, 1547-1562, https://doi.org/10.5194/gmd-8-1547-2015.

Marsland, S. J., J. A. Church, N. L. Bindoff, and G. D. Williams, 2007: Antarctic coastal polynya response to climate change. J. Geophys. Res., 112, C07009, https://doi.org/10.1029/2005JC003291.

Marson, J. M., P. G. Myers, X. Hu, and J. Le Sommer, 2018: Using vertically integrated ocean fields to characterize Greenland icebergs' distribution and lifetime. Geophys. Res. Lett., 45, 4208-4217, https://doi.org/10.1029/2018GL077676.

Martin, T., and A. Adcroft, 2010: Parameterizing the fresh-water flux from land ice to ocean with interactive icebergs in a coupled climate model. Ocean Modell., 34, 111-124, https:// doi.org/10.1016/j.ocemod.2010.05.001.

Martin-Español, A., and Coauthors, 2016: Spatial and temporal Antarctic ice sheet mass trends, glacio-isostatic adjustment, and surface processes from a joint inversion of satellite altimeter, gravity, and GPS data. J. Geophys. Res. Earth Surf., 121, 182-200, https://doi.org/10.1002/2015JF003550.

Mathiot, P., A. Jenkins, C. Harris, and G. Madec, 2017: Explicit representation and parametrised impacts of under ice shelf seas in the $z^{*}$ coordinate ocean model NEMO 3.6. Geosci. Model Dev., 10, 2849-2874, https://doi.org/10.5194/gmd-10-2849-2017.

Menéndez, C. G., V. Serafini, and H. Le Treut, 1999: The effect of sea-ice on the transient atmospheric eddies of the Southern Hemisphere. Climate Dyn., 15, 659-671, https://doi.org/ 10.1007/s003820050308.

Merino, N., J. L. Sommer, G. Durand, N. C. Jourdain, G. Madec, P. Mathiot, and J. Tournadre, 2016: Antarctic icebergs melt over the Southern Ocean: Climatology and impact on sea ice. Ocean Modell., 104, 99-110, https://doi.org/10.1016/j.ocemod. 2016.05.001.

- N. C. Jourdain, J. L. Sommer, H. Goosse, P. Mathiot, and G. Durand, 2018: Impact of increasing Antarctic glacial freshwater release on regional sea-ice cover in the Southern Ocean. Ocean Modell., 121, 76-89, https://doi.org/10.1016/ j.ocemod.2017.11.009.

Morrison, A. K., M. H. England, and A. M. Hogg, 2015: Response of Southern Ocean convection and abyssal overturning to surface buoyancy perturbations. J. Climate, 28, 4263-4278, https://doi.org/10.1175/JCLI-D-14-00110.1.

Nicholls, K. W., S. Østerhus, K. Makinson, T. Gammelsrød, and E. Fahrbach, 2009: Ice-ocean processes over the continental shelf of the southern Weddell Sea, Antarctica: A review. Rev. Geophys., 47, RG3003, https://doi.org/10.1029/2007RG000250.

Paolo, F. S., H. A. Fricker, and L. Padman, 2015: Volume loss from Antarctic ice shelves is accelerating. Science, 348, 327-331, https://doi.org/10.1126/science.aaa0940.

Parkinson, C. L., 2019: A 40-y record reveals gradual Antarctic sea ice increases followed by decreases at rates far exceeding the rates seen in the Arctic. Proc. Natl. Acad. Sci. USA, 116, 14 414-14 423, https://doi.org/10.1073/pnas.1906556116.

Pauling, A. G., C. M. Bitz, I. J. Smith, and P. J. Langhorne, 2016: The response of the Southern Ocean and Antarctic sea ice to freshwater from ice shelves in an Earth system model. J. Climate, 29, 1655-1672, https://doi.org/10.1175/JCLI-D-15-0501.1.

- I. J. Smith, P. J. Langhorne, and C. M. Bitz, 2017: Timedependent freshwater input from ice shelves: Impacts on Antarctic sea ice and the Southern Ocean in an Earth system model. Geophys. Res. Lett., 44, 10 454-10 461, https://doi.org/ 10.1002/2017GL075017.

Pezza, A. B., H. A. Rashid, and I. Simmonds, 2012: Climate links and recent extremes in Antarctic sea ice, high-latitude cyclones, southern annular mode and ENSO. Climate Dyn., 38, 57-73, https://doi.org/10.1007/s00382-011-1044-y.

Purich, A., M. H. England, W. Cai, A. Sullivan, and P. J. Durack, 2018: Impacts of broad-scale surface freshening of the Southern Ocean in a coupled climate model. J. Climate, 31, 2613-2632, https://doi.org/10.1175/JCLI-D-17-0092.1.

Rackow, T., C. Wesche, R. Timmermann, H. H. Hellmer, S. Juricke, and T. Jung, 2017: A simulation of small to giant 
Antarctic iceberg evolution: Differential impact on climatology estimates. J. Geophys. Res. Oceans, 122, 3170-3190, https://doi.org/10.1002/2016JC012513.

Rahmstorf, S., J. E. Box, G. Feulner, M. E. Mann, A. Robinson, S. Rutherford, and E. J. Schaffernicht, 2015: Exceptional twentieth-century slowdown in Atlantic Ocean overturning circulation. Nat. Climate Change, 5, 475-480, https://doi.org/ 10.1038/nclimate2554.

Richardson, G., M. R. Wadley, K. J. Heywood, D. P. Stevens, and H. T. Banks, 2005: Short-term climate response to a freshwater pulse in the Southern Ocean. Geophys. Res. Lett., 32, L03702, https://doi.org/10.1029/2004GL021586.

Ridley, J. K., E. W. Blockley, A. B. Keen, J. G. L. Rae, A. E. West, and D. Schroeder, 2018: The sea ice model component of HadGEM3-GC3.1. Geosci. Model Dev., 11, 713-723, https:// doi.org/10.5194/gmd-11-713-2018.

Rignot, E., J. L. Bamber, M. R. van den Broeke, C. Davis, Y. Li, W. J. van de Berg, and E. van Meijgaard, 2008: Recent Antarctic ice mass loss from radar interferometry and regional climate modelling. Nat. Geosci., 1, 106-110, https://doi.org/10.1038/ngeo102.

— S. Jacobs, J. Mouginot, and B. Scheuchl, 2013: Ice-shelf melting around Antarctica. Science, 341, 266-270, https:// doi.org/10.1126/science.1235798.

Russell, J. L., R. J. Stouffer, and K. W. Dixon, 2006: Intercomparison of the Southern Ocean circulations in IPCC coupled model control simulations. J. Climate, 19, 4560-4575, https://doi.org/ 10.1175/JCLI3869.1.

Schloesser, F., T. Friedrich, A. Timmermann, R. M. DeConto, and D. Pollard, 2019: Antarctic iceberg impacts on future Southern Hemisphere climate. Nat. Climate Change, 9, 672-677, https:// doi.org/10.1038/s41558-019-0546-1.

Sévellec, F., and A. V. Fedorov, 2016: AMOC sensitivity to surface buoyancy fluxes: Stronger ocean meridional heat transport with a weaker volume transport? Climate Dyn., 47, 1497-1513, https://doi.org/10.1007/s00382-015-2915-4.

Shepherd, A., and et al, 2018: Mass balance of the Antarctic ice sheet from 1992 to 2017. Nature, 558, 219-222, https://doi.org/ 10.1038/s41586-018-0179-y.

Silva, T. A. M., G. R. Bigg, and K. W. Nicholls, 2006: Contribution of giant icebergs to the Southern Ocean freshwater flux. J. Geophys. Res., 111, C03004, https://doi.org/10.1029/ 2004JC002843.

Silvano, A., S. R. Rintoul, B. Peña-Molino, W. R. Hobbs, E. van Wijk, S. Aoki, T. Tamura, and G. D. Williams, 2018: Freshening by glacial meltwater enhances melting of ice shelves and reduces formation of Antarctic Bottom Water. Sci. Adv., 4, eaap9467, https://doi.org/10.1126/sciadv.aap9467.

Sloyan, B. M., 2006: Antarctic bottom and lower circumpolar deep water circulation in the eastern Indian Ocean. J. Geophys. Res., 111, C02006, https://doi.org/10.1029/ 2005JC003011.

Smith, I. J., P. J. Langhorne, T. G. Haskell, H. Joe Trodahl, R. Frew, and M. Ross Vennell, 2001: Platelet ice and the landfast sea ice of McMurdo Sound, Antarctica. Ann. Glaciol., 33, 21-27, https://doi.org/10.3189/172756401781818365.

,,-- R. Frew, R. Vennell, and T. Haskell, 2012: Sea ice growth rates near ice shelves. Cold Reg. Sci. Technol., 83-84, 57-70, https://doi.org/10.1016/j.coldregions.2012.06.005.

Stammerjohn, S. E., D. G. Martinson, R. C. Smith, X. Yuan, and D. Rind, 2008: Trends in Antarctic annual sea ice retreat and advance and their relation to El Niño-Southern Oscillation and southern annular mode variability. J. Geophys. Res., 113, C03S90, https://doi.org/10.1029/2007JC004269.
Stouffer, R. J., D. Seidov, and B. Haupt, 2007: Climate response to external sources of freshwater: North Atlantic versus the Southern Ocean. J. Climate, 20, 436-448, https://doi.org/ 10.1175/JCLI4015.1.

Stern, A. A., A. Adcroft, O. Sergienko, and G. Marques, 2017: Modeling tabular icebergs submerged in the ocean. J. Adv. Model. Earth Syst., 9, 1948-1972, https://doi.org/10.1002/ 2017MS001002.

Storkey, D., and Coauthors, 2018: UK Global Ocean GO6 and GO7: A traceable hierarchy of model resolutions. Geosci. Model Dev., 11, 3187-3213, https://doi.org/10.5194/gmd-113187-2018.

Sutterley, T. C., I. Velicogna, E. Rignot, J. Mouginot, T. Flament, M. R. Van Den Broeke, J. M. Van Wessem, and C. H. Reijmer, 2014: Mass loss of the Amundsen Sea Embayment of West Antarctica from four independent techniques. Geophys. Res. Lett., 41, 8421-8428, https://doi.org/10.1002/ 2014GL061940.

Swart, N. C., and J. C. Fyfe, 2013: The influence of recent Antarctic ice sheet retreat on simulated sea ice area trends. Geophys. Res. Lett., 40, 4328-4332, https://doi.org/10.1002/grl.50820.

Timmermann, R., and H. H. Hellmer, 2013: Southern Ocean warming and increased ice shelf basal melting in the twentyfirst and twenty-second centuries based on coupled ice-ocean finite-element modelling. Ocean Dyn., 63, 1011-1026, https:// doi.org/10.1007/s10236-013-0642-0.

Tournadre, J., N. Bouhier, F. Girard-Ardhuin, and F. Rémy, 2015: Large icebergs characteristics from altimeter waveforms analysis. J. Geophys. Res. Oceans, 120, 1954-1974, https:// doi.org/10.1002/2014JC010502.

Turner, J., and Coauthors, 2009: Non-annular atmospheric circulation change induced by stratospheric ozone depletion and its role in the recent increase of Antarctic sea ice extent. Geophys. Res. Lett., 36, L08502, https://doi.org/10.1029/2009GL037524.

- , T. J. Bracegirdle, T. Phillips, G. J. Marshall, and J. S. Hosking, 2013: An initial assessment of Antarctic sea ice extent in the CMIP5 models. J. Climate, 26, 1473-1484, https:// doi.org/10.1175/JCLI-D-12-00068.1.

van Aken, H. M., 2007: The Oceanic Thermohaline Circulation: An Introduction. Atmospheric and Oceanographic Sciences Library, Vol. 39, Springer-Verlag, 326 pp., https://doi.org/ 10.1007/978-0-387-48039-8.

van den Berk, J., S. S. Drijfhout, and W. Hazeleger, 2019: Atlantic salinity budget in response to Northern and Southern Hemisphere ice sheet discharge. Climate Dyn., 52, 52495267, https://doi.org/10.1007/s00382-018-4444-4.

Weaver, A. J., O. A. Saenko, P. U. Clark, and J. X. Mitrovica, 2003: Meltwater pulse 1A from Antarctica as a trigger of the BøllingAllerød warm interval. Science, 299, 1709-1713, https://doi.org/ 10.1126/science.1081002.

Williams, K. D., and Coauthors, 2018: The Met Office Global Coupled Model 3.0 and 3.1 (GC3.0 and GC3.1) configurations. J. Adv. Model. Earth Syst., 10, 357-380, https://doi.org/10.1002/2017MS001115.

Williams, S. D., P. Moore, M. A. King, and P. L. Whitehouse, 2014: Revisiting GRACE Antarctic ice mass trends and accelerations considering autocorrelation. Earth Planet. Sci. Lett., 385, 12-21, https://doi.org/10.1016/j.epsl.2013.10.016.

Yuan, N., M. Ding, J. Ludescher, and A. Bunde, 2017: Increase of the Antarctic sea ice extent is highly significant only in the Ross Sea. Sci. Rep., 7, 41096, https://doi.org/10.1038/srep41096.

Zunz, V., and H. Goosse, 2015: Influence of freshwater input on the skill of decadal forecast of sea ice in the Southern Ocean. Cryosphere, 9 , 541-556, https://doi.org/10.5194/tc-9-541-2015. 